\title{
EARLINET: potential operationality of a research network
}

M. Sicard ${ }^{1,2}$, G. D’Amico ${ }^{3}$, A. Comerón ${ }^{1}$, L. Mona ${ }^{3}$, L. Alados-Arboledas ${ }^{4}$, A. Amodeo ${ }^{3}$, H. Baars ${ }^{5}$, J. M. Baldasano ${ }^{6,7}$, L. Belegante ${ }^{8}$, I. Binietoglou ${ }^{8}$, J. A. Bravo-Aranda ${ }^{9}$, A. J. Fernández ${ }^{10}$, P. Fréville ${ }^{11}$, D. García-Vizcaíno ${ }^{1}$, A. Giunta ${ }^{3}$, M. J. Granados-Muñoz ${ }^{4}$, J. L. Guerrero-Rascado ${ }^{4}$, D. Hadjimitsis ${ }^{12}$, A. Haefele ${ }^{13}$, M. Hervo ${ }^{11}$, M. Iarlori ${ }^{14}$, P. Kokkalis ${ }^{15}$, D. Lange ${ }^{1,2}$, R. E. Mamouri ${ }^{12}$, I. Mattis ${ }^{16}$, F. Molero ${ }^{10}$, N. Montoux ${ }^{11}$, A. Muñoz ${ }^{1}$, C. Muñoz Porcar ${ }^{1}$, F. Navas-Guzmán ${ }^{17}$, D. Nicolae ${ }^{8}$, A. Nisantzi ${ }^{12}$, N. Papagiannopoulos ${ }^{3}$, A. Papayannis ${ }^{15}$, S. Pereira ${ }^{18}$, J. Preißler ${ }^{19}$, M. Pujadas ${ }^{10}$, V. Rizi ${ }^{14}$, F. Rocadenbosch ${ }^{1,2}$, K. Sellegri ${ }^{11}$, V. Simeonov ${ }^{13}$, G. Tsaknakis ${ }^{15}$, F. Wagner ${ }^{16}$, and G. Pappalardo ${ }^{3}$

${ }^{1}$ Dept. of Signal Theory and Communications, Remote Sensing Lab. (RSLab), Universitat Politècnica de Catalunya, Barcelona, Spain

${ }^{2}$ Ciències i Tecnologies de l'Espai - Centre de Recerca de l'Aeronàutica i de l'Espai/Institut d'Estudis Espacials de Catalunya (CTE-CRAE/IEEC), Universitat Politècnica de Catalunya, Barcelona, Spain

${ }^{3}$ Istituto di Metodologie per l'Analisi Ambientale (CNR-IMAA), C. da S. Loja, 85050 Tito Scalo, Potenza, Italy

${ }^{4}$ Departamento de Física Aplicada, Universidad de Granada, Granada, Spain

${ }^{5}$ Leibniz Institute for Tropospheric Research, Leipzig, Germany

${ }^{6}$ Earth Sciences Department, Barcelona Supercomputing Center - Centro Nacional de Supercomputación, Barcelona, Spain

${ }^{7}$ Environmental Modeling Laboratory, Technical University of Catalonia, Barcelona, Spain

${ }^{8}$ National Institute of R\&D for Optoelectronics, Magurele, Ilfov, Romania

${ }^{9}$ Laboratoire Meteorologie Dinamique (LMD), École Polytechnique, Palaiseau, France

${ }^{10}$ Centro de Investigaciones Energéticas, Medioambientales y Tecnológicas (CIEMAT), Madrid, Spain

${ }^{11}$ Observatoire de Physique du Globe, Laboratoire de Météorologie Physique (LaMP-CNRS), Clermont-Ferrand, France

${ }^{12}$ Cyprus University of Technology, Limassol, Cyprus

${ }^{13}$ Federal Office of Meteorology and Climatology MeteoSwiss, Payerne, Switzerland

${ }^{14}$ CETEMPS, Dipartimento di Scienze Fisiche e Chimiche, Università degli Studi, L'Aquila, Italy

${ }^{15}$ Laser Remote Sensing Unit, Physics Dept., National Technical University of Athens, Athens, Greece

${ }^{16}$ Deutscher Wetterdienst, Observatorium Hohenpeißenberg, Hohenpeißenberg, Germany

${ }^{17}$ Institute of Applied Physics (IAP), University of Bern, Bern, Switzerland

${ }^{18}$ Évora Geophysics Center, University of Évora, Évora, Portugal

${ }^{19}$ Centre for Climate and Air Pollution Studies (C-CAPS), National University of Ireland Galway, University Road, Galway, Ireland

Correspondence to: M. Sicard (msicard@tsc.upc.edu)

Received: 27 April 2015 - Published in Atmos. Meas. Tech. Discuss.: 1 July 2015

Revised: 6 October 2015 - Accepted: 15 October 2015 - Published: 2 November 2015 
Abstract. In the framework of ACTRIS (Aerosols, Clouds, and Trace Gases Research Infrastructure Network) summer 2012 measurement campaign (8 June-17 July 2012), EARLINET organized and performed a controlled exercise of feasibility to demonstrate its potential to perform operational, coordinated measurements and deliver products in near-real time. Eleven lidar stations participated in the exercise which started on 9 July 2012 at 06:00 UT and ended $72 \mathrm{~h}$ later on 12 July at 06:00 UT. For the first time, the single calculus chain (SCC) - the common calculus chain developed within EARLINET for the automatic evaluation of lidar data from raw signals up to the final products - was used. All stations sent in real-time measurements of a $1 \mathrm{~h}$ duration to the SCC server in a predefined netcdf file format. The pre-processing of the data was performed in real time by the SCC, while the optical processing was performed in near-real time after the exercise ended. 98 and $79 \%$ of the files sent to SCC were successfully pre-processed and processed, respectively. Those percentages are quite large taking into account that no cloud screening was performed on the lidar data. The paper draws present and future SCC users' attention to the most critical parameters of the SCC product configuration and their possible optimal value but also to the limitations inherent to the raw data. The continuous use of SCC direct and derived products in heterogeneous conditions is used to demonstrate two potential applications of EARLINET infrastructure: the monitoring of a Saharan dust intrusion event and the evaluation of two dust transport models. The efforts made to define the measurements protocol and to configure properly the SCC pave the way for applying this protocol for specific applications such as the monitoring of special events, atmospheric modeling, climate research and calibration/validation activities of spaceborne observations.

\section{Introduction}

Atmospheric aerosols have important effects on life on Earth: they can be toxic, by composition or by structure (size or shape); they deteriorate visibility (haze and fog occurrence depends on aerosols); ecosystems are affected by significant mass transport; etc. They also have an effect on many areas of the atmospheric sciences: they influence atmospheric chemistry by providing reactive surfaces (stratospheric ozone depletion, summer smog); they affect the radiation budget and hence the temperature distribution within the atmosphere and on the ground, including change in spectral distribution; etc. In the three areas of climate, weather, and air quality, the aerosol contribution is one of the most uncertain contributions. As an example, the aerosol radiative effects on climate, the aerosol-radiation interactions (direct and semidirect effects: the direct interaction of radiation with aerosol absorption and scattering properties) and the aerosol-cloud interactions (indirect effects: modification of clouds forma- tion and their properties by aerosols), are still estimated with very large uncertainties according to the Intergovernmental Panel on Climate Change (IPCC) (IPCC, 2014). In the area of air quality, chemistry transport models often use near-surface measurements extrapolated to the vertical column when observations of the aerosol vertical distribution are missing. This leads to substantial uncertainties in the forecast of particulate matter (Sartelet et al., 2007; Roustan et al., 2010).

The difficulties in quantifying the aerosol contribution, not only locally but on a global scale, are due to the following:

- their high variability in space and time and, as a consequence, on their non-localized distribution, mostly due to medium- and long-range transport and short mean life time;

- the geographical extension of the sources: some are localized, others are distributed over large volumes;

- the large number of processes that lead to their production;

- the numerous and heterogeneous processes through which aerosols can interact during their lifetime: nucleation, condensation, coagulation and deposition.

The lidar technique is a powerful tool to assess the aerosol stratification, i.e. the vertical structure of the aerosol layers (bottom, top and thickness). Combined backscatter and Raman lidar systems allow the retrieval of the aerosol optical properties (backscatter and extinction coefficients). Advanced lidar systems (see Sect. 2.3 for the definition) can provide in addition aerosol microphysical properties (fine and coarse fraction of the extinction coefficient, effective radius, complex refractive index and single scattering albedo).

Ground-based lidar networks are especially valuable to get vertical profiling of aerosols at scales from regional to global. In an effort to facilitate knowledge and data exchange between lidar groups, the Global Atmosphere Watch (GAW) Aerosol Lidar Observation Network (GALION) was formed envisioning the cooperation among existing lidar networks and contributions from individual stations (Hoff et al., 2008). At present, GALION consists of eight existing and developing networks (two operative networks operating backscatter systems working on a constant (24/7) basis, and six research networks) in different regions of the globe:

- the Asian Dust Network (AD-Net)

- the Latin American Lidar Network (LALINET)

- the Commonwealth of Independent States Lidar Network (CIS-LiNet)

- the European Aerosol Research Lidar Network (EARLINET)

- the Micro Pulse Lidar Network (MPLNET) 
- the Network for the Detection of Atmospheric Composition Change (NDACC)

- the NOAA Cooperative Remote Sensing Science and Technology (CREST) Lidar network (CLN)

- the Canadian Operational Research Aerosol Lidar Network (CORALNet).

Among those networks, EARLINET is the only one operating a majority of advanced Raman systems (Pappalardo et al., 2014).

EARLINET (www.earlinet.org), established in 2000, is the first coordinated aerosol lidar network whose key goal is the provision of a comprehensive, quantitative, and statistically significant database on the spatial and temporal aerosol distribution on a continental scale (Bösenberg, et al., 2001; Pappalardo et al., 2014). At present, the network includes 27 active stations distributed over Europe (Pappalardo et al., 2014). Lidar observations within the network are performed on a regular schedule of one daytime measurement per week around 12 solar time, when the boundary layer is usually well developed, and two night time measurements per week, with low background light, in order to perform Raman extinction measurements. In addition to the routine measurements, further observations are devoted to monitoring of special events such as desert dust outbreaks (e.g. Ansmann et al. 2003; Mona et al., 2006; Papayannis et al., 2008; Guerrero-Rascado et al., 2008, 2009; Mamouri et al., 2013; Nisantzi et al., 2015), forest fires (e.g., Müller et al., 2007a; Amiridis et al., 2009; Alados-Arboledas et al., 2011, Nisantzi et al., 2014), photochemical smog (Carnuth et al., 2002), and volcanic eruptions (e.g., Pappalardo et al., 2004a; Wang et al., 2008; Mattis et al., 2010; Ansmann et al., 2010; Groß et al., 2011; Papayannis et al., 2012; Sicard et al., 2012; Wiegner et al., 2012; Navas-Guzmán et al., 2013; Pappalardo et al., 2013). In June 2006, EARLINET started correlative measurements for the space-borne lidar on board CALIPSO (Cloud-Aerosol Lidar and Infrared Pathfinder Satellite Observation) (Pappalardo et al., 2010). Although EARLINET was not conceived as an operational network, it already proved its capability of providing data in near-real time under special circumstances (Pappalardo et al., 2013). On the other hand, coordinated observations with data delivered in nearreal time are of prime importance in the areas of weather and air quality and also for the monitoring of plumes from special events. Referring to lidar products, the GAW Report No. 178 (2008) states that "For assimilation into chemical weather forecast models excellent temporal coverage, high reliability, and near-real-time delivery are the key properties requested".

In July 2012 EARLINET performed a controlled exercise of feasibility to demonstrate its potential to perform operational, coordinated measurements. To this aim, the single calculus chain (SCC), the common calculus chain developed within EARLINET for the automatic evaluation of lidar data from raw signals up to the final products (D'Amico et al., 2012, 2015a, b; Mattis et al., 2015), was used for the first time in an automated way. The amount and the quality of the data obtained during the exercise, as well as the lessons learnt from it, offer promising perspectives for applications such as climate research (model evaluation, aerosol transport and tracers, impact on radiation), air quality (assessment and forecast) and the monitoring of plumes from special events.

The objective of this paper is to demonstrate the capabilities of the research network EARLINET to perform operational, coordinated measurements and deliver lidar products in near-real time. The paper deals first with logistic and technical issues (organization, measurements protocol, data harmonization), then with the SCC configuration and statistical results and finally with two case studies using the data obtained during the exercise on how lidar products obtained either in real or near-real time can be used in two of the applications listed above. Those two examples illustrate the new perspectives that, through this exercise, EARLINET can offer to the modeling community and monitoring agencies. The paper is organized as follows: it describes the organization of the exercise and the systems involved in Sect. 2, the SCC, its configuration, and statistical results during the exercise in Sect. 3; Sect. 4 gives a description of the synoptic conditions during the exercise, presents the two examples mentioned above and a list of more general perspectives; conclusions are given in Sect. 5.

\section{Campaign setup and systems}

\subsection{Campaign motivation and setups}

Two of the most challenging objectives of the exercise in terms of operationality were the following: (1) to perform continuous measurements during a relatively long period of time and to deliver raw data in real time, and (2) to run automatically in real time for the first time the SCC. In that sense, a special effort was made to operate the systems taking into account that EARLINET lidar stations are mostly formed by research systems that currently operate neither automatically nor unmanned. A strong coordination effort was also made to harmonize the operational scheme, as well as data products and name conventions, to provide homogeneous documentation for systems and data and to establish common access points for the data.

The time window for starting the operationality exercise was fixed between 2 and 12 July 2012, while its duration was fixed to 3 complete days, i.e. $72 \mathrm{~h}$, in order to fall within ACTRIS (Aerosols, Clouds, and Trace Gases Research Infrastructure Network) summer 2012 measurement campaign (8 June-17 July 2012) aimed mainly at the study of Saharan dust. The ACTRIS campaign gave support to two international field campaigns during summer 2012: 
- the European Monitoring and Evaluation Programme (EMEP) (Espen Yttri et al., 2012) and

- the Chemistry-Aerosol Mediterranean Experiment (ChArMEx) (Dulac et al., 2012).

In order to optimize the chances to have a particularly interesting situation (such as an intrusion of Saharan dust or high levels of $\mathrm{PM}_{10}$ ), weather prediction models, forecast models of dust such as NAAPS (Navy Aerosol Analysis and Prediction System; Christensen, 1997), Skiron (Nickovic et al., 2001) and BSC-DREAM8b v2 (Barcelona Supercomputing Center - Dust Regional Atmospheric Model 8 bins; Pérez et al., 2006a, b; Basart et al., 2012), and air quality models were consulted prior to initiate the experiment.

\subsection{Measurements protocol}

The measurements protocol was defined on the basis of the ongoing EARLINET regular measurements (Pappalardo et al., 2009) and refined to fulfill the exercise objectives:

- duration of the measurement per recorded file: $60 \mathrm{~min}$;

- raw temporal resolution: a number that 30 min should be a multiple of in order to guarantee a minimum integration time of $30 \mathrm{~min}$ for all systems;

- range resolution: the system raw resolution;

- all wavelengths available should be recorded;

- no cloud screening is performed by the stations. Instead, each station is responsible for providing information about the maximum height (ma.s.l.) up to which the profile is cloud free;

- strict and accurate synchronization of all stations to $[\mathrm{hh}]:[\mathrm{mm}=00 \pm 1]$;

- creation of one single netcdf file of the raw signals (power) per measurement;

- upload to the SCC central server.

A first test of the operationality exercise took place on 23 April 2012, in which the stations of Granada, Barcelona, L'Aquila and Potenza participated. It lasted $10 \mathrm{~h}$ between 07:00 and 17:00 UT. Broken clouds were present above all the stations and intermittent rain also occurred over Italy. The objective of the test was to check the correct functioning of the measurement protocol, the data format of all systems and the reliability of the automatic pre-processing of the SCC. The pre-processed files were delivered by the SCC within a few minutes after the measurements ended. A total of 33 files were sent to the SCC that pre-processed successfully 27 of them $(84 \%)$.

\subsection{Lidar systems}

Eleven EARLINET stations around the Mediterranean Basin decided to participate to the exercise. From west to east (see Fig. 1 and Table 1):

- EV, Évora, Portugal $\left(7.911^{\circ} \mathrm{W}, 38.568^{\circ} \mathrm{N}, 290 \mathrm{~m}\right.$ a.s.l.)

- MA, Madrid, Spain (3.730 W, $45.450^{\circ}$ N, 663 m a.s.1.)

- GR, Granada, Spain (3.610 W, 37.160 N, 680 m a.s.l.)

- BA, Barcelona, Spain $\left(2.112^{\circ} \mathrm{E}, 41.389^{\circ} \mathrm{N}\right.$, 115 m a.s.l.)

- CL, Clermont-Ferrand, France $\left(3.111^{\circ} \mathrm{E}, 45.761^{\circ} \mathrm{N}\right.$, 420 m a.s.1.)

- PA, Payerne, Switzerland (6.943 ${ }^{\circ} \mathrm{E}, 46.813^{\circ} \mathrm{N}$, 491 m a.s.l.)

- LA, L'Aquila, Italy $\left(13.350^{\circ} \mathrm{E}, 42.368^{\circ} \mathrm{N}, 656 \mathrm{~m}\right.$ a.s.1.)

- PO, Potenza, Italy $\left(15.720^{\circ} \mathrm{E}, 40.600^{\circ} \mathrm{N}, 760 \mathrm{~m}\right.$ a.s.l.)

- AT, Athens, Greece $\left(23.780^{\circ}\right.$ E, $37.960^{\circ}$ N, 212 m a.s.l.)

- BU, Bucharest, Romania $\left(26.029^{\circ}\right.$ E, $44.348^{\circ} \mathrm{N}$, 93 m a.s.l.)

- LM, Limassol, Cyprus (33.040 E $34.640^{\circ} \mathrm{N}, 8 \mathrm{~m}$ a.s.1.)

Seven stations operated an advanced lidar system (green labels in Fig. 1). Advanced lidars consist of at least three elastic wavelengths and two Raman wavelengths and allow aerosol typing and potentially microphysics retrieval. Four stations operated a Raman lidar system (orange labels in Fig. 1). Raman lidars consist of at least one elastic wavelength and one Raman wavelength and allow for the retrieval of the extinction and the backscatter coefficients at one wavelength. Six stations also performed measurements of the linear particle depolarization ratio at one elastic wavelength. Even though PA performed the measurements during the whole campaign, their data are not presented in this work because of a lack of manpower to follow on with the analysis of their data.

Figure 1 also indicates the stations where a sun photometer is co-located. In total, eight stations have a co-located sun photometer, all of them being part of the Aerosol Robotic Network (AERONET) (Holben et al., 1998). Sun photometers allow for the retrieval of columnar values of parameters such as the aerosol optical depth (AOD), the Angström exponent (AE), the single scattering albedo or the size distribution among others. Sun photometers are also a precious cooperative instrument to lidars for constraining elastic lidar inversions (Landulfo et al., 2003; Reba et al., 2010) and for microphysics retrieval (Wagner et al., 2013; Chaikovsky et al., 2015, Binietoglou et al., 2015).

The data quality of all EARLINET systems is assured by inter-comparisons at instrument level using transportable reference systems (Matthias et al., 2004; Sicard et al., 2009; 


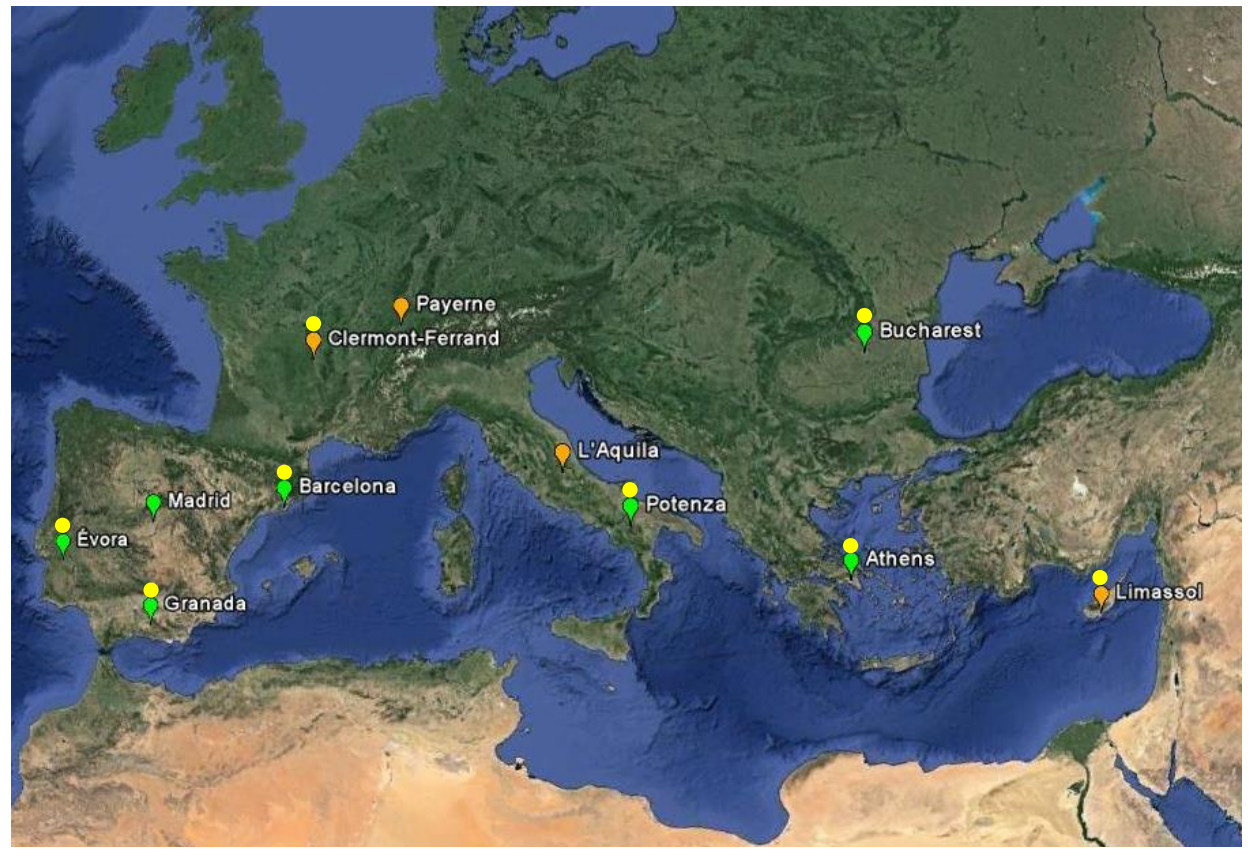

Figure 1. Geographical position of the 11 stations that participated in the exercise. Green labels indicate advanced lidar systems; orange labels indicate Raman lidar systems. Yellow circles indicate co-located sun photometers.

Table 1. Wavelengths and temporal resolution, $\Delta t$, of the systems involved in the exercise.

\begin{tabular}{|c|c|c|c|c|c|c|c|c|c|c|c|c|c|c|}
\hline \multirow[t]{3}{*}{ Station } & \multirow{3}{*}{351} & \multicolumn{6}{|c|}{$\begin{array}{l}\text { Elastic wavelengths } \\
\qquad(\mathrm{nm})\end{array}$} & \multicolumn{6}{|c|}{$\begin{array}{l}\text { Raman wavelengths } \\
\text { (nm) }\end{array}$} & \multirow[t]{3}{*}{$\begin{array}{l}\Delta t \\
\text { (s) }\end{array}$} \\
\hline & & & 355 & & & 32 & & 1064 & 382 & 387 & 393 & 408 & 607 & \\
\hline & & Total & $/ /^{1}$ & $\perp^{2}$ & Total & $/ /^{1}$ & $\perp^{2}$ & & & & & & & \\
\hline EV & & $\mathrm{x}$ & & & $\mathrm{x}$ & & $\mathrm{x}$ & $\mathrm{x}$ & & $\mathrm{x}$ & & & $\mathrm{x}$ & 30 \\
\hline MA & & $\mathrm{x}$ & & & $\mathrm{x}$ & & & $\mathrm{x}$ & & $\mathrm{X}$ & & & $\mathrm{x}$ & 60 \\
\hline GR & & $\mathrm{x}$ & & & & $\mathrm{x}$ & $\mathrm{x}$ & $\mathrm{x}$ & & $\mathrm{X}$ & & $\mathrm{x}$ & $\mathrm{x}$ & 60 \\
\hline BA & & $\mathrm{x}$ & & & $\mathrm{x}$ & & & $\mathrm{x}$ & & $\mathrm{x}$ & & $\mathrm{x}$ & $\mathrm{x}$ & 60 \\
\hline CL & & & $\mathrm{x}$ & $\mathrm{x}$ & & & & & & $\mathrm{x}$ & & $\mathrm{x}$ & & 60 \\
\hline PA & & $\mathrm{x}$ & & & & & & & & $\mathrm{X}$ & & $\mathrm{x}$ & & 60 \\
\hline LA & $\mathrm{x}$ & & & & & & & & $\mathrm{x}$ & & $\mathrm{x}$ & & & 300 \\
\hline PO & & $\mathrm{x}$ & & & & $\mathrm{x}$ & $\mathrm{x}$ & $\mathrm{x}$ & & $\mathrm{x}$ & & & $\mathrm{x}$ & 60 \\
\hline AT & & $\mathrm{x}$ & $\mathrm{x}$ & $x$ & $\mathrm{x}$ & & & $\mathrm{x}$ & & $\mathrm{x}$ & & $\mathrm{x}$ & $\mathrm{x}$ & 60 \\
\hline BU & & $\mathrm{x}$ & & & & $\mathrm{x}$ & $\mathrm{x}$ & $\mathrm{x}$ & & $\mathrm{x}$ & & $\mathrm{x}$ & $\mathrm{x}$ & $60 \mathrm{~d} / 300 \mathrm{n}^{3}$ \\
\hline LM & & & & & & $\mathrm{x}$ & $\mathrm{x}$ & $\mathrm{x}$ & & & & & $\mathrm{x}$ & 48 \\
\hline
\end{tabular}

$1 / /$ indicates the parallel polarization component with respect to the laser polarization. ${ }^{2} \perp$ indicates the perpendicular polarization component with respect to the laser polarization. ${ }^{3} \mathrm{~d}$ indicates day and $\mathrm{n}$ night.

Freudenthaler et al., 2010; Molero et al., 2012, Wandinger et al., 2015). The data quality assurance also includes the intercomparison of elastic and Raman retrieval algorithms of each individual station (Böckmann et al., 2004; Pappalardo et al., 2004b; Sicard et al., 2009). Based on well-defined common standards and internal quality tests, the routinely performed quality-assurance exercises of lidar systems and algorithms ensure that the data products provided by the individual stations are homogeneous and continuously of highest possible reliability (Freudenthaler et al., 2015a). During the ongoing ACTRIS-2 project, the continuation of ACTRIS, new products and further improvements are foreseen based on ongoing activities, in particular, about linear depolarization ratio accuracy (Freudenthaler et al., 2010; Belegante et al., 2015; Bravo-Aranda et al., 2015; Freudenthaler et al., 2015b) and error characterization (Engelmann et al., 2015; Amodeo et al., 2015). 


\section{Real and near-real-time EARLINET single-calculus chain products}

\subsection{Presentation of the SCC}

The single calculus chain (SCC) is the standard tool for the automatic analysis of EARLINET data. It has been designed to provide quality assured aerosol products (according to EARLINET quality assurance program) starting from the raw lidar time series. Two different levels of quality assured products are made available: pre-processed range corrected signals and aerosol extinction and/or backscatter coefficients. The SCC is highly configurable and flexible to assure the automatic analysis of data coming from different type of lidars and, even for the same instrument, from different configurations. The SCC is composed by two independent but interconnected calculus modules: the EARLINET Lidar PreProcessor (ELPP) module providing the pre-processed range corrected signals corrected for instrumental effects and the EARLINET Lidar Data Analyzer (ELDA) for the calculation of the aerosol optical products from the ELPP outputs. All the input parameters needed for the lidar analysis are collected in a database and organized in terms of different lidar configurations. The modules ELPP and ELDA are automatically started and monitored by a dedicated daemon module when there are available input data not yet analyzed. The SCC is installed on a common server accessible by all EARLINET stations through a web interface which improves the user friendliness of the SCC. All the details of the SCC modules are described in this special issue (D'Amico at al., 2015a, b; Mattis et al., 2015).

For the exercise the SCC was configured to provide two kinds of aerosol products:

- SCC-1: pre-processed range-square corrected signal (RCS) in netcdf format generated by the ELPP module from the raw netcdf files submitted by each station. These products were generated in a full automatic way and in real time. At the same time the ELPP outputs were stored, an email was automatically sent to the contact point of the originating station. This email gave a real-time feedback from the SCC about the preprocessing status and revealed to be extremely useful for real time fine tuning the SCC configuration of each individual system and of its associated products.

- SCC-2: optical processed files generated by ELDA from SCC-1 products. These products are netcdf files containing the profiles of the aerosol optical coefficients: backscatter in daytime (using SCC system configurations defined for daytime condition for each lidar) and backscatter and extinction in nighttime (using SCC system configurations defined for nighttime for each lidar). The lidar configuration (daytime or nighttime) to use for the SCC analysis of each raw lidar time series is selected automatically; time series containing Raman channels are assigned to nighttime configuration while elasticonly data sets are analyzed using daytime configuration. The backscatter coefficients from elastic signals only (daytime) were retrieved with the iterative method (Di Girolamo et al., 1999; Masci, 1999), while the backscatter and extinction coefficients from the combination of elastic and Raman signals (nighttime) were retrieved with the method described in Ferrare et al. (1998). Both methods are implemented in the SCC (Mattis et al., 2015).

The netcdf files generated by ELDA are of two types:

- b-files (b for backscatter) contain one profile of the aerosol backscatter coefficient $\left(\mathrm{m}^{-1} \mathrm{sr}^{-1}\right)$ derived from the elastic backscatter signal only (daytime) or alternatively from the combination of an elastic and a Raman signal at the highest vertical resolution (nighttime).

- e-files (e for extinction) contain profiles of aerosol extinction coefficient $\left(\mathrm{m}^{-1}\right)$ and of aerosol backscatter coefficients at the same effective vertical resolution retrieved independently from the combination of an elastic and a Raman signal without a priori assumptions on the existing relationship between them.

Both types of files include the profile of the statistical error associated to the variables they contain. More details about b- and e-files can be found in Pappalardo et al. (2014).

\subsection{About the SCC product configurations}

The configuration of the retrieval products delivered by the SCC is set online via a web interface in real time either by each station PI or by the SCC developers. To guarantee the uniformity of the results, the configuration of the products generated during the exercise was set up by the SCC developers only. The configuration of a given product consists of defining a set of parameters (options) needed by ELPP and ELDA to perform the retrieval of that product. During the exercise, only three types of products were defined: the backscatter coefficient obtained with the elastic algorithm (daytime, b-files) and backscatter and extinction coefficients obtained with the Raman algorithm (nighttime, e-files). There are roughly two kinds of parameters to be fulfilled prior to the inversion: the general parameters (mandatory, used for all product types) and the specific parameters (depend on the product type). The specific parameters, which are, for example, the inversion method, the error method, the value of the lidar ratio, etc., are not critical in the inversion procedure. For that reason, only the general parameters are presented next. An exhaustive list of the parameters needed for the retrieval products of the SCC can be found in this special issue (D'Amico et al., 2015b; Mattis et al., 2015).

Table 2 summarizes all the general parameters and their setup during the exercise. The integration time was fixed to $3600 \mathrm{~s}$ so that ELPP outputs were $1 \mathrm{~h}$ averaged profiles. The 
Table 2. General parameters of the SCC product configuration set up for the exercise.

\begin{tabular}{|c|c|c|c|c|c|c|c|c|}
\hline \multirow{3}{*}{$\begin{array}{l}\text { Module } \\
\text { Parameter }\end{array}$} & \multicolumn{2}{|c|}{ ELPP } & \multicolumn{6}{|c|}{ ELDA } \\
\hline & \multirow{2}{*}{$\begin{array}{r}\text { Integration } \\
\text { time }\end{array}$} & \multirow{2}{*}{$\begin{array}{r}\text { Vertical } \\
\text { resolution }\end{array}$} & \multirow{2}{*}{$\begin{array}{l}\text { Min. } \\
\text { height }\end{array}$} & \multirow{2}{*}{$\begin{array}{r}\text { Max. } \\
\text { height }\end{array}$} & \multicolumn{2}{|c|}{ Detection limit } & \multirow{2}{*}{$\begin{array}{r}\text { Max. statistical } \\
\text { error }(<2 \mathrm{~km})\end{array}$} & \multirow{2}{*}{$\begin{array}{l}\text { Max. statistical } \\
\text { error }(>2 \mathrm{~km})\end{array}$} \\
\hline & & & & & Extinction & Backscatter & & \\
\hline Unit & $\mathrm{s}$ & $\mathrm{m}$ & $\mathrm{m}$ & $\mathrm{m}$ & $\mathrm{Mm}^{-1}$ & $\mathrm{Mm}^{-1} \mathrm{sr}^{-1}$ & $\%$ & $\%$ \\
\hline EV & 3600 & 60 & 250 & 15000 & 5 & 0.1 & 10 & 10 \\
\hline MA & 3600 & 60 & 250 & 15000 & 5 & 0.1 & 10 & 10 \\
\hline GR & 3600 & 60 & 500 & 15000 & 5 & 0.1 & 10 & 10 \\
\hline BA & 3600 & 60 & 250 & 15000 & 5 & 0.1 & 10 & 10 \\
\hline CL & 3600 & 60 & 250 & 15000 & 5 & 0.1 & 10 & 10 \\
\hline LA & 3600 & 60 & 250 & 15000 & 5 & 0.1 & 10 & 10 \\
\hline $\mathrm{PO}$ & 3600 & 60 & 250 & 15000 & 5 & 0.1 & 10 & 10 \\
\hline AT & 3600 & 60 & 250 & 12000 & 5 & 0.1 & 10 & 10 \\
\hline $\mathrm{BU}$ & 3600 & 60 & 250 & 15000 & 5 & 0.1 & 10 & 10 \\
\hline LM & 3600 & 60 & 250 & 15000 & 5 & 0.1 & 10 & 10 \\
\hline
\end{tabular}

vertical resolution of SCC-1 products (ELPP output) was fixed to $60 \mathrm{~m}$, the highest spatial resolution of the 10 systems involved in the exercise. The minimum and maximum heights represent the minimum and maximum altitude for the calculation of the product. The minimum height usually depends on the knowledge of the height of the full overlap, while the maximum height usually depends on the maximum range of useful signal or of acquisition. The last three parameters are quite critical in the inversion procedure. They were all set to the same values for each of the 10 systems in order to standardize the delivered products in terms of absolute and statistical errors. The first one, called "detection limit", is one of the two criteria of the automated, iterative vertical smoothing algorithm of ELDA, which optimizes the vertical smoothing in each altitude bin. Detection limit is a backscatter, or an extinction absolute value, defining the product maximum absolute uncertainty allowed. In an initial step, the product is calculated with the maximum allowable vertical smoothing (i.e. resulting in a maximum effective vertical resolution of 500 and $2000 \mathrm{~m}$ below and above $2 \mathrm{~km}$, respectively). In the following steps, the calculated absolute uncertainty is compared to the user-defined detection limit at each altitude bin. If the calculated absolute uncertainty stays below the user-defined detection limit, the smoothing window is reduced by one bin and the whole process is repeated (see Sect. 3.5 of Mattis et al. (2015) for more details). During the exercise, detection limit was set to $0.1 \mathrm{Mm}^{-1} \mathrm{sr}^{-1}$ for the backscatter coefficients and to $5 \mathrm{Mm}^{-1}$ for the extinction coefficient. No adjustment was allowed on those values to guarantee the same absolute uncertainty for all products, independently of the system. Those values are lower than the initial target accuracies estimated in the GAW Report No. 178 (2008) of $0.5 \mathrm{Mm}^{-1} \mathrm{sr}^{-1}$ for the backscatter coefficients and to $20 \mathrm{Mm}^{-1}$ for the extinction coefficient. The two other parameters are the maximum allowed statistical errors below and above $2 \mathrm{~km}$. The second criterion of the smoothing algorithm is based on them and they are also used in the estimation of the calibration factor. In the smoothing algorithm, they fix the maximum values that the calculated statistical errors cannot exceed at each altitude bin. The iterative procedure is exactly the same as for the detection limit parameter. In the estimation of the calibration factor, they fix the maximum values that the uncertainty of the calibration factor (calculated as the standard deviation of the signal in a certain altitude range; see Sect. 3.2.2 of Mattis et al. (2015) for more details) cannot exceed. During the exercise, the statistical error thresholds for the low and the high range were set to the same value of $10 \%$ for all products. Here again, no adjustment of those values was allowed to guarantee the same statistical error for all products, independently of the system. The same order of magnitude (10 and $5 \%$ for the backscatter retrieved from elastic and Raman algorithm, respectively; $10 \%$ for the extinction retrieved with the Raman algorithm) were estimated in the GAW Report No. 178 (2008). It is worth noting that relaxing the required uncertainties by increasing detection limit and/or the maximum allowed statistical errors would have led to a better (i.e. lower) effective vertical resolution and thus to larger uncertainties of the final product. In turn, it might have possibly increased the number of successful SCC inversions (at the cost of degrading the error on the final product). However, in view of the good statistics of the SCC results (see next Section) we believe that the values of the detection limit and of the maximum allowed statistical errors chosen for the exercise are close to be optimal values and that increasing them would have not yielded much better results.

\subsection{Statistics of the SCC results during the campaign}

As summarized in Table 3, a total of 665 files were sent to the SCC. The ELPP module was successful in pre-processing 650 of them $(98 \%)$. For a minor subset (15 files) the signal 
Table 3. Number of files at the different stages of the exercise and finally inverted by the SCC.

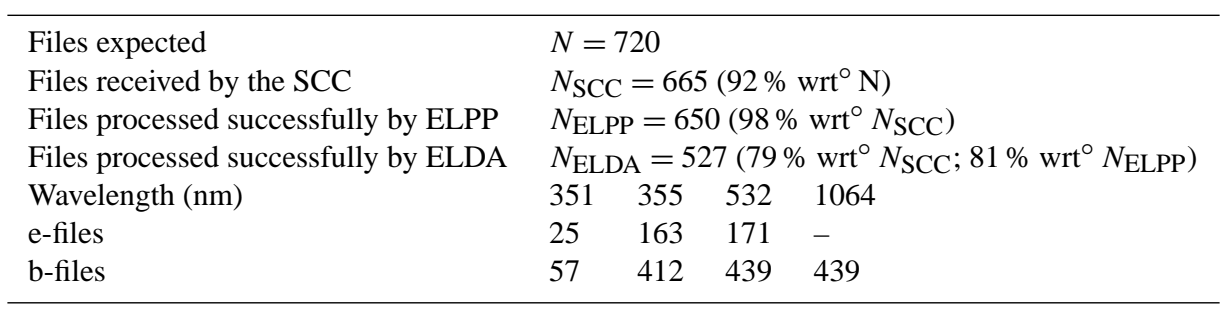

quality was not sufficient to pass ELPP quality control tests in two procedures: in applying the gluing algorithm and the dead time correction to photon-counting channels. The automatic procedure of gluing between analog and corresponding photon-counting signals consists of enhancing the detected dynamic range using the analog profile in the strong signal region and the photon-counting profile in the weak signal region. The gluing algorithm implemented in ELPP tries to find the optimal region where to combine the two signals performing a set of statistical and consistency tests (D'Amico et al., 2015b) to assure a reliable and stable combined signal. When such a region was not found, ELPP stopped the analysis and returned a specific error code. This is illustrated in the left panel of Fig. 2. On a total of 15 cases for which the raw data quality was not sufficient to pass ELPP quality control tests, 8 are the results of the gluing procedure, 6 refers to a problem in applying dead time correction to photon-counting channel and finally in 1 case there are format problems in the submitted raw netcdf file.

The number of SCC-2 profiles is 527, which represents $79 \%$ of all submitted files $(81 \%$ of the files that passed ELPP). This percentage is quite large taking into account that no cloud screening was performed on lidar data. If we remove from the statistics the number of measurements identified a posteriori as contaminated by clouds (see next paragraph), this percentage increases to $87 \%$ (89\% of the files that passed ELPP). Most of the remaining $13 \%$ (11\% with respect to the files that passed ELPP) that was not successfully inverted by ELDA were due to low signal to noise ratio in at least one of the channel of the system. Even though the same number of stations run systems equipped with channels at $355 \mathrm{~nm}$ as visible ones (eight stations, see Table 1 ignoring PA), the number of b-files at $355 \mathrm{~nm}$ (412) is lower than at $532 \mathrm{~nm}$ (439). This can be explained by considering that the shorter is the wavelength the weaker is the contrast between aerosol and molecular contribution in lidar signals. As a consequence, in general, the retrieval of the aerosol backscatter coefficient is more problematic in the ultraviolet than in the visible or in the infrared spectral regions.

The reasons for which ELDA could not successfully perform the optical processing of SCC-1 data are shown in the right panel of Fig. 2. There are a total of 123 cases. About half of them (60 cases, i.e. $49 \%$ of them) refer to the automatic search of a reliable and stable region for the calibration of aerosol backscatter coefficient. This search is unsuccessful typically when the pre-processed lidar signals are characterized by a poor signal-to-noise ratio (SNR) or when there is cloud contamination in the lidar profiles. To calculate the calibration factor, ELDA calculates a mean value and standard deviation in a calibration window. If that standard deviation is lower than a pre-defined maximum allowable threshold, the mean value is used to calibrate the profile. If it is larger, ELDA tries to find another calibration window within the predefined altitude region (mostly covering the total free troposphere). However, depending on the aerosol loading and vertical distribution, sometimes no calibration window with sufficiently low standard deviation can be identified within the free troposphere (typically high aerosol loading at low altitude resulting in a poor SNR at high altitude or aerosols present up to high altitudes). In those cases, ELDA returns the error code "No valid data points for calibration". In particular, it has been verified for the SCC-1 products that 28 (out of 60) cases for which ELDA could not find a calibration interval with the required accuracy contained clouds. The rest of the cases (32) were due mostly to problems in inverting the ultraviolet wavelengths ( 351 and $355 \mathrm{~nm}, 28$ cases) and only occasionally $1064 \mathrm{~nm}$ (4 cases). The inversion at $532 \mathrm{~nm}$ was always successful. Among those 32 cases, the impossibility of finding a calibration interval occurred a little more during daytime when applying the elastic algorithm (18 cases) than during nighttime when applying the Raman algorithm (14 cases). All 32 cases occurred at four stations (CL: 1; LA: 10, PO: 8, AT: 13) which means that the SCC could always find a suitable calibration interval at the other six stations (leaving apart the cloud cases). This is probably due to a generally better SNR at those six stations or due to different atmospheric aerosol loadings.. In 42 cases, ELDA could not successfully perform the optical processing because of a not-converging iterative procedure in the search of a solution for the calculation of the backscatter profile with the elastic algorithm. It has been verified for the SCC-1 products that in 11 (out of 42) cases, the profiles contained clouds. In the remaining 31 cases, the iterative procedure did not converge at $355 \mathrm{~nm}$. Among those 31 cases, 23 occurred in MA and the rest in five other stations (GR: 1, BA: 1, CL: 2, AT: 1, BU: 3). This situation, when ELDA cannot find a solution for the calculation of the backscatter profile with the elastic algorithm, is common especially for shorter wavelengths (here 


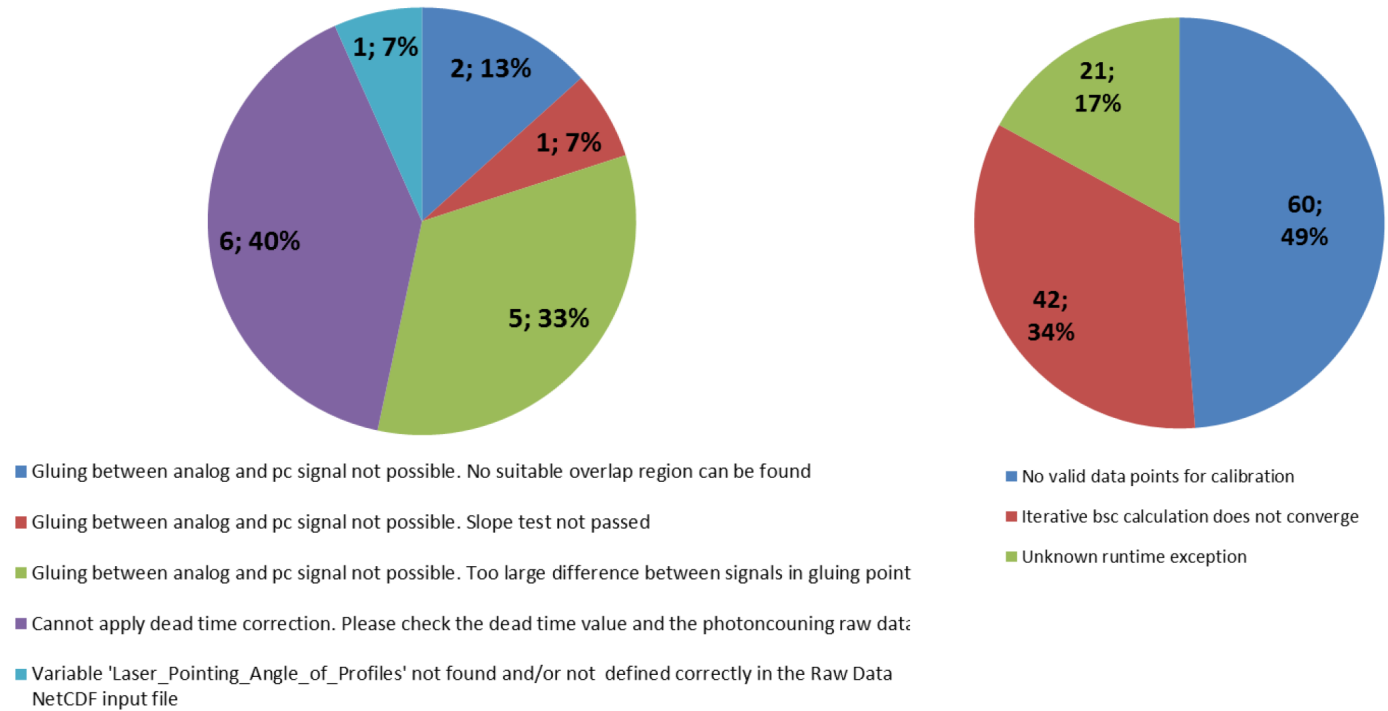

Figure 2. Number and frequency (in \%) of the reasons for which either the pre-processing (ELPP, left) or the optical processing (ELDA, right) could not derive a solution. The color legend indicates the error code.

exclusively since it always occurred at $355 \mathrm{~nm}$ ) when there is a poor SNR or a strong contamination of clouds in the lidar signals. Finally, in a non-negligible number of cases (21, $17 \%$ of the cases for which ELDA could not successfully perform the optical processing) the reason has a computing origin. We have checked that in 17 cases, the profiles were contaminated by clouds and that in 4 cases (all of them in BA) the computing error was raised during the elastic inversion at $355 \mathrm{~nm}$.

In summary, this statistical analysis allows for the identification of the most critical/sensitive products and steps of the optical processing module of the SCC. Throughout the exercise, with the exception of the cloud cases, ELDA is unable to finalize the inversion with the required accuracy in two main steps of the processing: in the search of a calibration interval and in the iterative procedure of the method used to invert the backscatter coefficient from elastic signals only. When the inversion is unsuccessful, it occurs mostly at $355 \mathrm{~nm}(94 \%$ of the cases) and occasionally at $1064 \mathrm{~nm}(6 \%)$. Among the unsuccessful inversions at $355 \mathrm{~nm}, 78 \%$ of them occurred during the elastic inversion (daytime) and $22 \%$ during the Raman inversion (nighttime). Low SNR of the $355 \mathrm{~nm}$ channels, especially during daytime, emerges as a critical issue common to most of the systems involved in the exercise.

The SCC works as an online tool: regularly new SCC versions including debugging and improvements are provided. When a new version is set up, the whole data set is inverted again automatically, so that the number of retrieved profiles may change, and hopefully increase. Currently the cloud screening is under development as a separate tool and different approaches to perform a reliable and robust cloud screening at network level are in testing phase. Once implemented in the SCC, it will identify cloudy conditions before the analysis which will allow us to gain computing time but not to increase the number of successful inversions.

\section{Potential operationality of EARLINET}

This section aims at demonstrating the potential operationality of EARLINET. After a brief description of the synoptic situation during the campaign, this demonstration is made by means of two examples: the monitoring of a Saharan dust intrusion event and the evaluation of two dust transport models thanks to the variety and continuity of SCC products. The last subsection deals with the more general perspectives that this type of exercise offers to the atmospheric community.

\subsection{Synoptic situation during the 9-12 July 2012, measurement exercise}

During the time window for the "GO" (2-12 July 2012) no strong levels of $\mathrm{PM}_{10}$ were predicted around the Mediterranean Basin. On 3 July, a weak intrusion of Saharan dust was predicted for 5 July. The dust would come from the Libyan coasts towards south Italy and then would move eastward. Maxima of dust concentration were expected on 6-7 July. The forecast on 4 July confirmed the intrusion of 5 July with two important changes: Spain would also be affected by the intrusion, and the event would strengthen starting on 8 July. The "GO" was fixed to Monday 9 July at 06:00 UT. The exercise ended on Thursday 12 July at 06:00 UT. The days of interest, 9, 10, 11 and 12 July, are hereinafter noted as J09, $\mathrm{J} 10, \mathrm{~J} 11$ and $\mathrm{J} 12$, respectively.

Figure 3 shows the synoptic situation centered over the Mediterranean Basin in terms of sea level pressure for the three periods $00-24,24-48$, and $48-72 \mathrm{~h}$ after the "GO". 

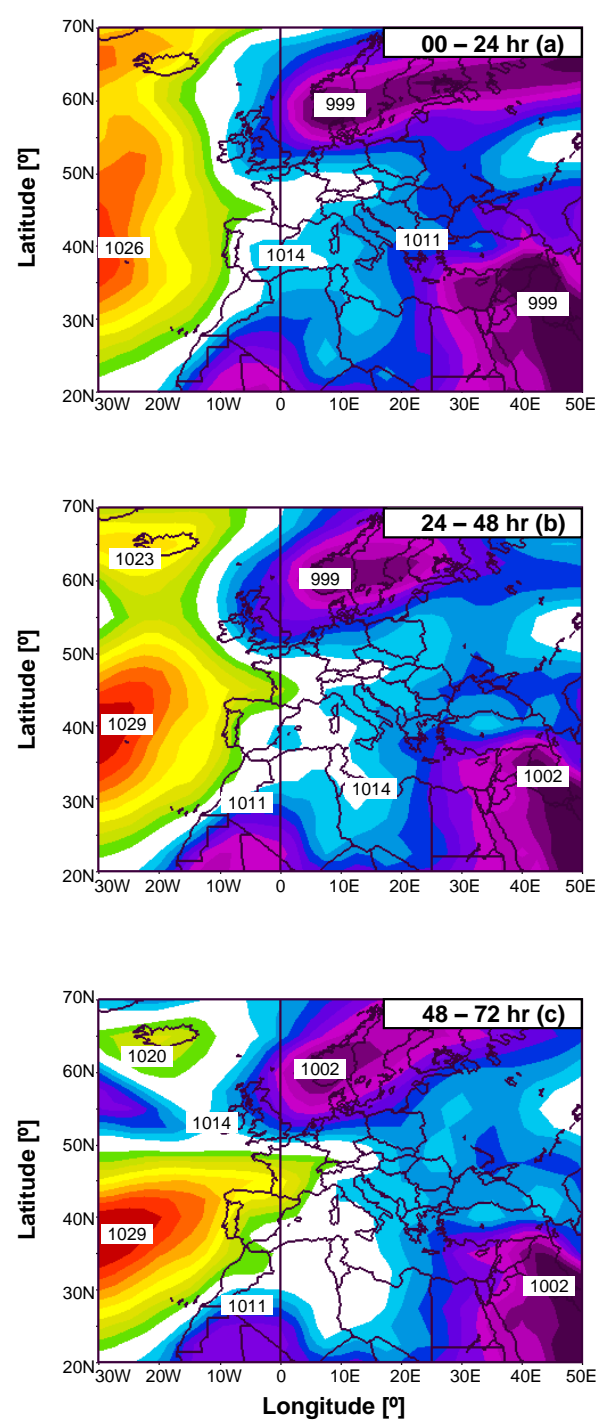

Figure 3. Mean synoptic situation from the NCEP/NCAR Reanalysis project at (a) 00-24, (b) 24-48 and (f) 48-72 h after the "GO". Purple and red colors represent low and high pressures, respectively.

Each map is a composite map from the NCEP/NCAR (National Centers for Environmental Prediction/National Center for Atmospheric Research) Reanalysis project showing the mean sea level pressure for each period. The period is characterized by the presence of a stable Azores high and three low pressure systems centered over southern Norway, Saudi Arabia and Mali. A warm front associated with the low pressure system located over southern Norway produced unstable weather over northern Europe and high temperatures and fair weather over western and central Europe. This situation generated generally clear skies above the northern part of the Mediterranean Basin, the region of interest, which persisted during the period as the Azores High moved slightly eastward. Easterly winds were also predominant over Europe.
The Saharan dust intrusion forecasted to start on 5 July occurred indeed. It was a rather moderate event that did not affect all the stations involved in the 9-12 July measurement exercise as forecasted by dust transport models. The AERUS-GEO daily aerosol optical depth at $675 \mathrm{~nm}$ on J09, J10, J11 and J12 from the MSG/SEVIRI sensor is shown in Fig. 4a-d. Figure 4 shows how the dust, transported above northern Morocco, Algeria, and Tunisia, hits the southeastern coasts of Spain as well as southern Italy, disperses above the western Mediterranean Basin and moves slowly eastwards. It also shows the intensity decrease of the dust event from J09 until J12. It is not clear if the dust plume reaches Greece and Romania. According to Fig. 4 the only stations that are very likely to have been hit by the event are GR, LA and PO. The maximum dust concentration forecast by the BSCDREAM8b model was $\sim 170-180 \mu \mathrm{g} \mathrm{m}^{-3}$ over LA and PO on J09 at 12:00 UT and over GR on J12 at 12:00 UT (after the exercise ended).

In addition to mineral dust, fires are also frequent around the Mediterranean Basin at this period of the year. The fire overlays from the MODIS sensor onboard Aqua and Terra satellites are shown in Fig. 4e-h. Many fires are present on the northern coast of Algeria, in Sicily and in southern Italy. The fire smoke could be mixed with the dust plume which is visible on MODIS images. A series of fires are also present from west to east between the countries of the ex-Yugoslavia and southern Romania.

\subsection{Example 1: monitoring of a Saharan dust intrusion event}

This section aims at illustrating how the SCC products that EARLINET is able to provide in real and near-real time (under some given circumstances) can be used to monitor not only a special event (here a Saharan dust intrusion event) but more generally the aerosol 4-D (spatial and temporal) characterization. A more comprehensive analysis of the dust microphysics during the operationality exercise can be found in Granados-Muñoz et al. (2015). For that reason, the emphasis is put more on the SCC-1 and SCC-2 products than on the proper monitoring of the dust event.

\subsubsection{Time-height series of the semi-attenuated backscatter coefficient (not a SCC product)}

Time-height series, also called quicklooks, of the attenuated backscatter coefficient not corrected for the total transmissivity are shown in Fig. 5 for EV, BA and BU at $1064 \mathrm{~nm}$. The attenuated backscatter not corrected for the total transmissivity was calculated by fitting the RCS to the molecular slope in an aerosol-free region. To do so, the RCS, $P(z)$, at altitude $z$ was fitted to the profile of the molecular backscatter coefficient, $\beta_{\mathrm{m}}(z)$, in an aerosol-free region centered around a reference altitude, $z_{\text {ref. }}$. The attenuated backscatter not corrected for the total transmissivity, $\beta_{\text {att-uncorr }}$ and the attenu- 

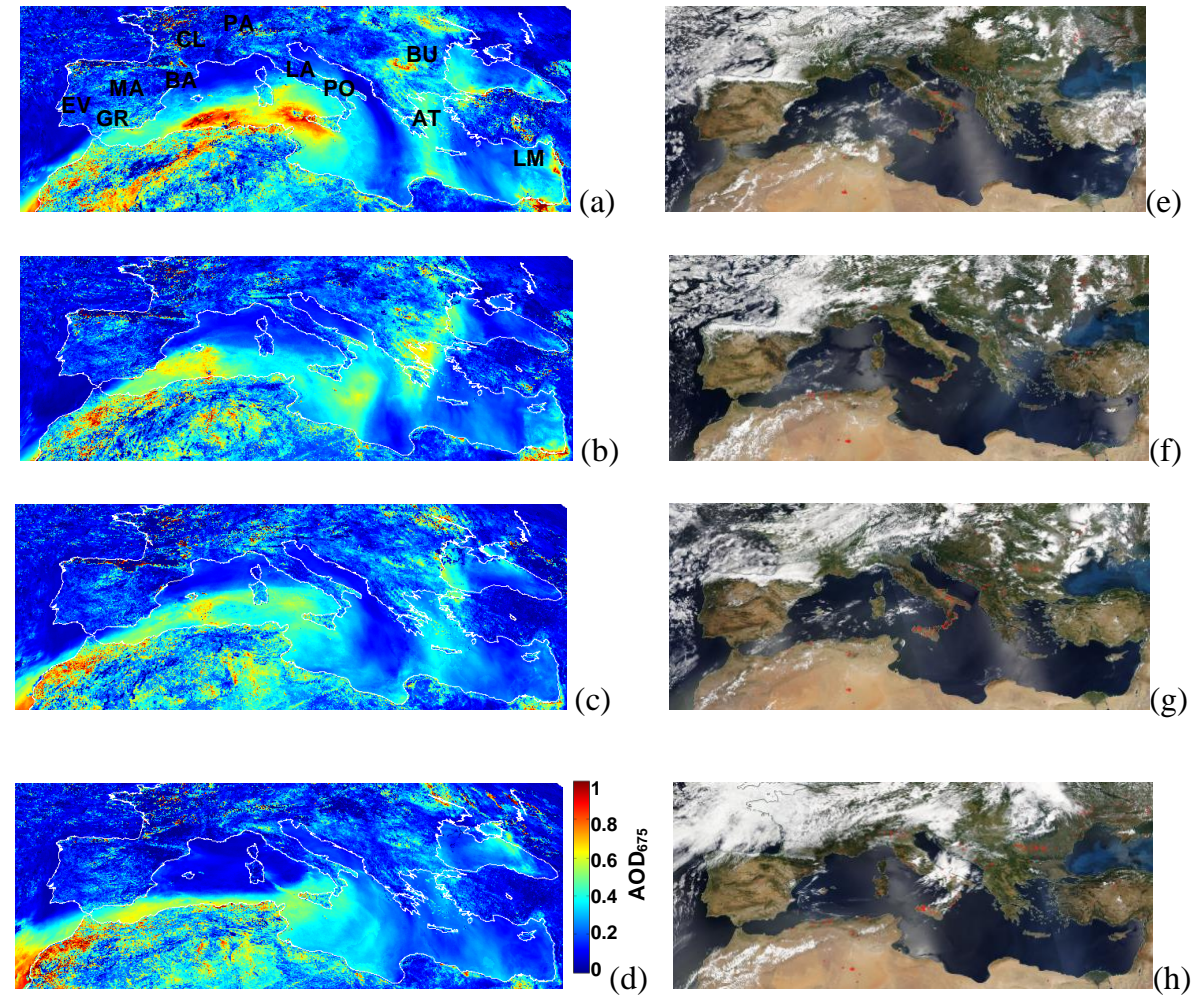

Figure 4. MSG/SEVIRI AERUS-GEO daily AOD at $675 \mathrm{~nm}$ on (a) J09, (b) J10, (c) J11 and (d) J12. Aqua/ and Terra/MODIS fire overlays on (e) J09, (f) J10, (g) J11 and (h) J12 from https://earthdata.nasa.gov/labs/worldview/. The legend of (d) applies for (a), (b) and (c).

ated backscatter, $\beta_{\text {att }}$, are related through:

$\beta_{\text {att-uncorr }}(z)=\frac{\beta_{\mathrm{T}}(z) T_{\mathrm{T}}^{2}(z)}{T_{\mathrm{T}}^{2}\left(z_{\mathrm{ref}}\right)}=\frac{\beta_{\mathrm{att}}(z)}{T_{\mathrm{T}}^{2}\left(z_{\mathrm{ref}}\right)}$,

where $\beta_{\mathrm{T}}$ and $T_{\mathrm{T}}$ refer to the total backscatter coefficient and the total transmissivity, respectively. The thickness of the fitting region was fixed to $1 \mathrm{~km}$ around the reference altitude which was selected within the range $5.5-7.5 \mathrm{~km}$ depending on the aerosol stratification. The quicklooks shown here were calculated from the raw signals contained in the input netcdf files received by the SCC. Quicklooks are not yet a standard product of the SCC, but their representation gives an excellent overview of the aerosol load vertical distribution and temporal evolution at each station.

Three very different situations are observed in Fig. 5. In $\mathrm{EV}$, almost no clouds are observed during the whole event. The temporal evolution of $\beta_{\text {att-uncorr }}$ has a marked diurnal cycle clearly correlated with that of the planetary boundary layer (PBL). Hardly any lofted layers are observed above the PBL. In BA, $\beta_{\text {att-uncorr is quite strong in the first kilo- }}$ meter where the PBL top is usually detected (Sicard et al., 2011). In the quicklook, many layers of different intensities are observed in the troposphere and up to $5 \mathrm{~km}$. The aerosol stratification in $\mathrm{BU}$ is also complex. The PBL formation is clearly visible every morning after 06:00-07:00 UT. At all times, aerosol layers are observed in the troposphere and up to $6 \mathrm{~km}$.

\subsubsection{RCS profiles at several wavelengths (SCC-1 products)}

The products from ELPP are illustrated by means of the RCS profiles at 355 and $532 \mathrm{~nm}$ on $\mathrm{J} 11$ which are shown in Fig. 6 for the same stations as in Fig. 5. The RCS units are arbitrary units. The $x$ axis limit of Fig. 6 has been optimized to highlight the layers with aerosols. The regions where the RCS profiles exceed the selected $x$ axis limit are usually contaminated by clouds. At all three stations, no overlap correction was performed; thus the first hundreds of meters above the lidar stations are clearly affected by the incomplete overlap effect and are not representative of the aerosol load. The time series of the hourly RCS profiles show clearly the periods contaminated by clouds: between 05:00 and 08:00 UT in EV, between 02:00 and 05:00 UT and between 07:00 and 11:00 UT in BA, and at 02:00, 04:00, 05:00 and 07:00 UT in $\mathrm{BU}$. The features commented in the former paragraph about the quicklooks, such as the diurnal cycle of the PBL in EV or the multi-layer stratification in BA and BU, are also visible here. We recall that ELPP generates an intermediate product that is not easily usable for direct science purposes but that is 

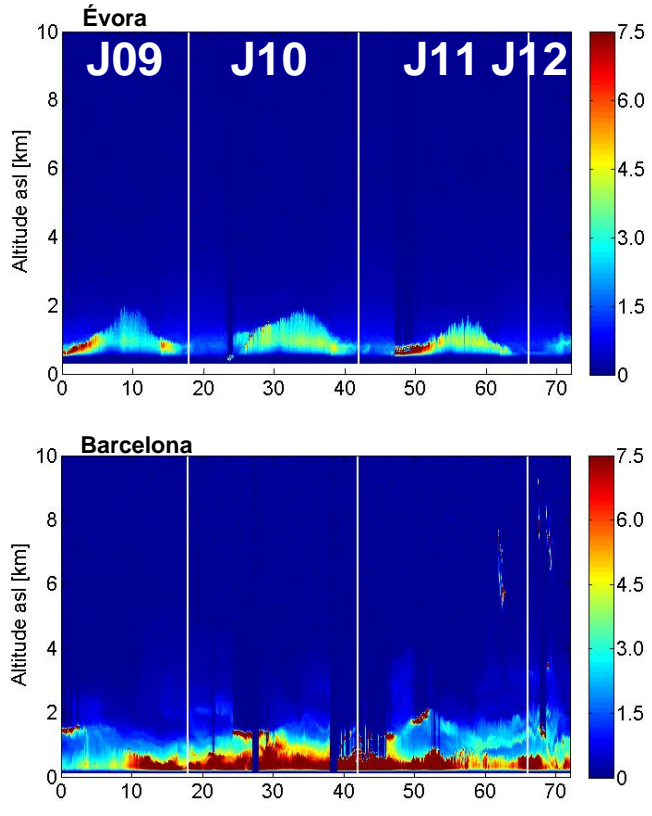

(a)

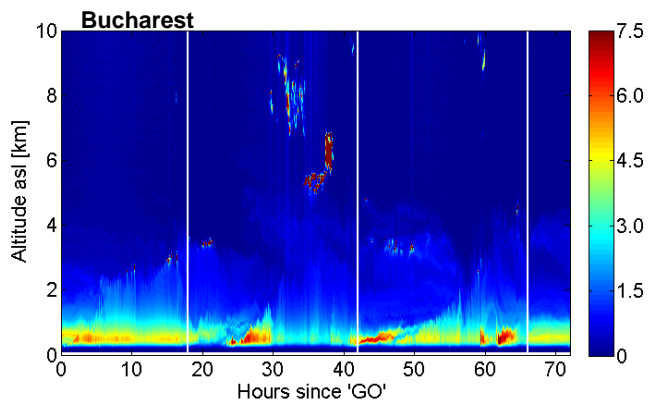

Figure 5. Quicklooks of the attenuated backscatter not corrected for the total transmissivity [a. u.] at $1064 \mathrm{~nm}$ in (a) Évora, (b) Barcelona and (c) Bucharest. The white vertical lines indicate a change in the date. The attenuated backscatter is not a product of the SCC.

extremely useful for validation of and/or assimilation in air quality and climate models (see Sect. 4.4).

\subsubsection{Backscatter coefficient profiles at several wavelengths (SCC-2 products)}

The ELDA module of the SCC provides inversions of the aerosol optical properties. During daytime all elastic wavelengths are inverted by means of the iterative method ( $\mathrm{Di}$ Girolamo et al., 1999; Masci, 1999; Mattis et al., 2015). Figures 7 and 8 show the temporal evolution of the profiles of the backscatter coefficient at all stations with at least two wavelengths on J10. Figure 7 reports the results at the Iberian stations and Fig. 8 at the central and eastern European stations. All the profiles are reported as a function of height above mean sea level. This is the reason why the different stations present profiles starting at different heights in agreement with their respective altitudes above sea level. Some inversions are missing in the middle of the day in MA, BA,
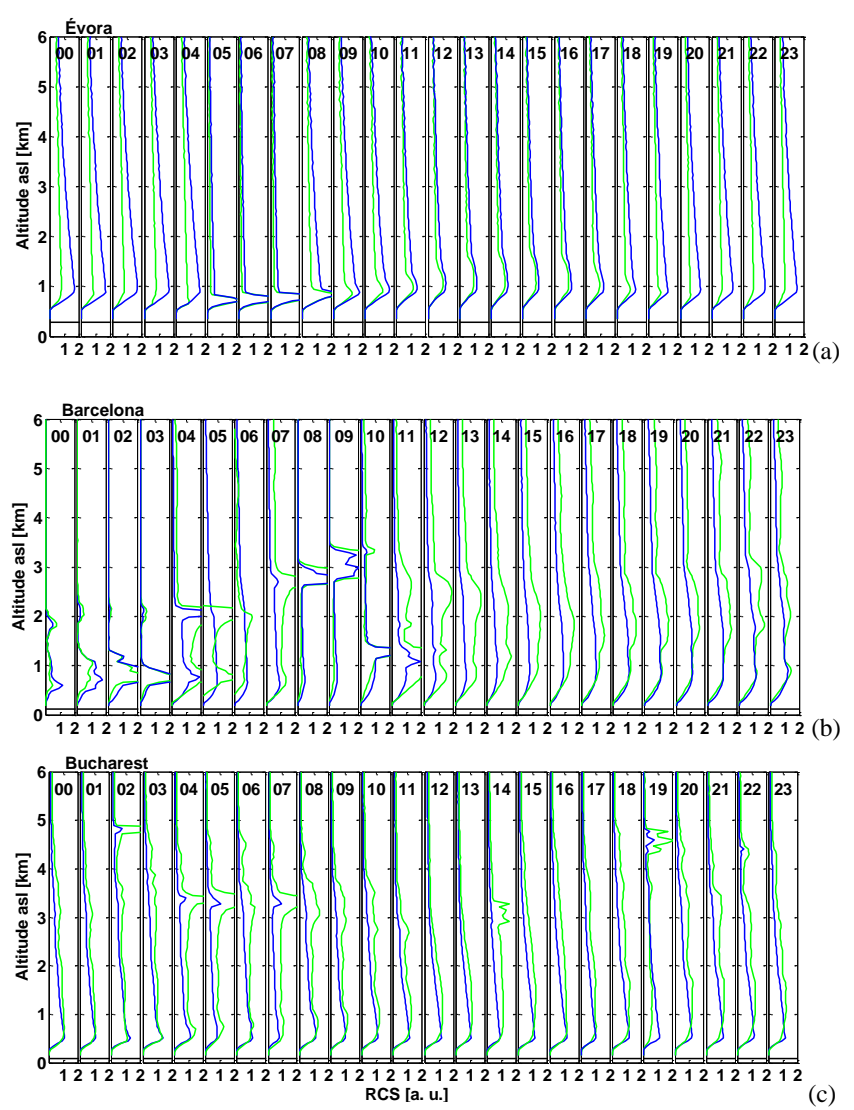

Figure 6. $24 \mathrm{~h}$ evolution of the hourly RCS profiles (SCC-1 product) at 355 (blue lines) and $532 \mathrm{~nm}$ (green lines) on J11 in (a) Évora, (b) Barcelona and (c) Bucharest. The numbers in the top of the plots indicate the time in UT. The horizontal black lines represent the station's altitude asl.

$\mathrm{PO}, \mathrm{BU}$ and LM. In MA all the daytime missing inversions are due to a not-converging iterative procedure during the elastic inversion at $355 \mathrm{~nm}$. We manually checked that no cloud was present. The BA system presents the peculiarity of pointing not at zenith but at $52^{\circ}$ off zenith. This peculiarity is a clear disadvantage since the optical thickness in the atmospheric path is $1 / 1 \cos \left(52^{\circ}\right) \cos \left(52^{\circ}\right) \sim 1.65$ larger than if the system had been pointing at zenith. In addition to this handicap, the BA lidar system had a misalignment problem in the optical channel at $355 \mathrm{~nm}$ which resulted in a very poor SNR at $355 \mathrm{~nm}$. Because of that low SNR, the calibration interval was sometimes taken in a region where the useful signal was hardly distinguishable from the noise. In those cases, and despite the successful SCC processing, the profiles of backscatter coefficient at $355 \mathrm{~nm}$ are qualitatively much different than the profiles at 532 or $1064 \mathrm{~nm}$ (see at 04:00, 16:00, 17:00 and 18:00 UT). The five missing inversions in BA were due to the following: two computing errors while applying the elastic inversion at $355 \mathrm{~nm}$, one error in the search of a calibration interval in ELDA, one error in the gluing procedure in ELPP, and one measurement not 

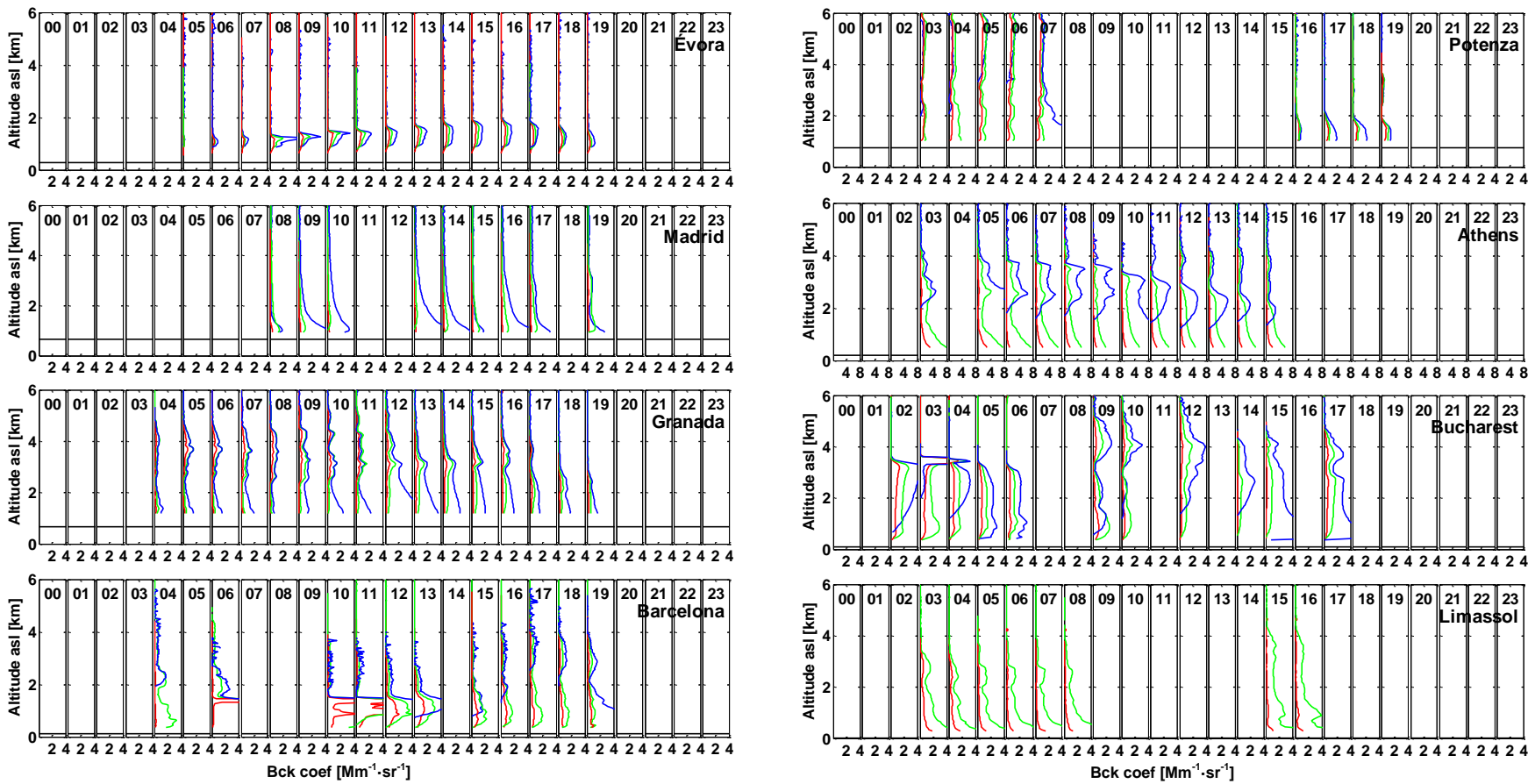

Figure 7. Time series of elastic-inverted backscatter coefficient profiles (SCC-2 product) on $\mathrm{J} 10$ at 355 (blue), $532 \mathrm{~nm}$ (green) and $1064 \mathrm{~nm}$ (red) at the Iberian stations ordered west to east. The numbers below the top axis indicate the time in UT. The horizontal black lines represent the station's altitude asl.

performed. It is worth noting that even in the presence of low clouds the inversion can be successful (see BA plot at 06:00 and 10:00-13:00 UT and also BU at 02:00-04:00 UT). Because no cloud-screening procedure is implemented yet in the SCC, if the low clouds are optically thin, ELDA is able to find a calibration interval (above them) and to perform the inversion. However such inversions are not yet useful for science because ELDA is not yet made to handle clouds. In PO, in 8 cases, among which 1 of them was identified a posteriori as contaminated by clouds, ELDA could not find a calibration interval. In BU, the missing inversions at 07:00 and 08:00 UT were due to the not-converging iterative procedure. We verified a posteriori that the three-afternoon missing inversions in BU contained clouds that can be actually seen in Fig. 5c. In LM, no measurements were performed between 09:00 and 14:00 UT on J10 because of technical problems with the laser transmitter. It is worth noting that the SCC is configured so that it returns the full set of products of a defined system configuration only if the inversion of all products is performed successfully (pre-processing and optical processing). If a single product is not retrieved successfully, no inversion at all is delivered. It is a way to guarantee a high quality of all the products defined in a system configuration and delivered by the SCC. The drawback is that if the quality of the raw data is not sufficient for the analysis, the raw data do not pass the quality control tests of the analysis algorithms

Figure 8. Idem as Fig. 7 at the central and eastern European stations ordered west to east.

and the SCC does not return any result for the corresponding measurement. During nighttime the SNR is higher than during daytime, and the inversion (mostly at 355 or at $532 \mathrm{~nm}$ ) is statistically more successful during nighttime than during daytime, especially around the hours when the sun is close to zenith (Mattis et al., 2015).

Except near the surface where none of the systems is corrected for the incomplete overlap and for obvious cloudy cases, the backscatter coefficient generally does not exceed $3 \mathrm{Mm}^{-1} \mathrm{sr}^{-1}$. In AT, the backscatter coefficient at $355 \mathrm{~nm}$ is higher, reaching regularly $6 \mathrm{Mm}^{-1} \mathrm{sr}^{-1}$ in the tropospheric layers. Except in EV where the troposphere is particularly clean during the whole period, tropospheric aerosols are present generally between 2 and $5 \mathrm{~km}$ and sometimes up to $6 \mathrm{~km}$ (in PO). In GR, the aerosol layer above $2-3 \mathrm{~km}$ has a very low spectral dependency (especially visible between the profiles at 355 and $532 \mathrm{~nm}$ ) which indicates the presence of mineral dust. This low spectral dependency is also observed on the profiles of PO above $4 \mathrm{~km}$ in the early hours of J10, which also confirms the presence of mineral dust but at a higher altitude compared to GR.

\subsubsection{Extinction coefficient profiles at several wavelengths (SCC-2 products)}

During nighttime the Raman algorithm allows for the retrieval of the extinction coefficient in addition to the backscatter coefficient. The profiles of the extinction coefficient at 355 and at $532 \mathrm{~nm}$ are shown in Fig. 9 at two sta- 

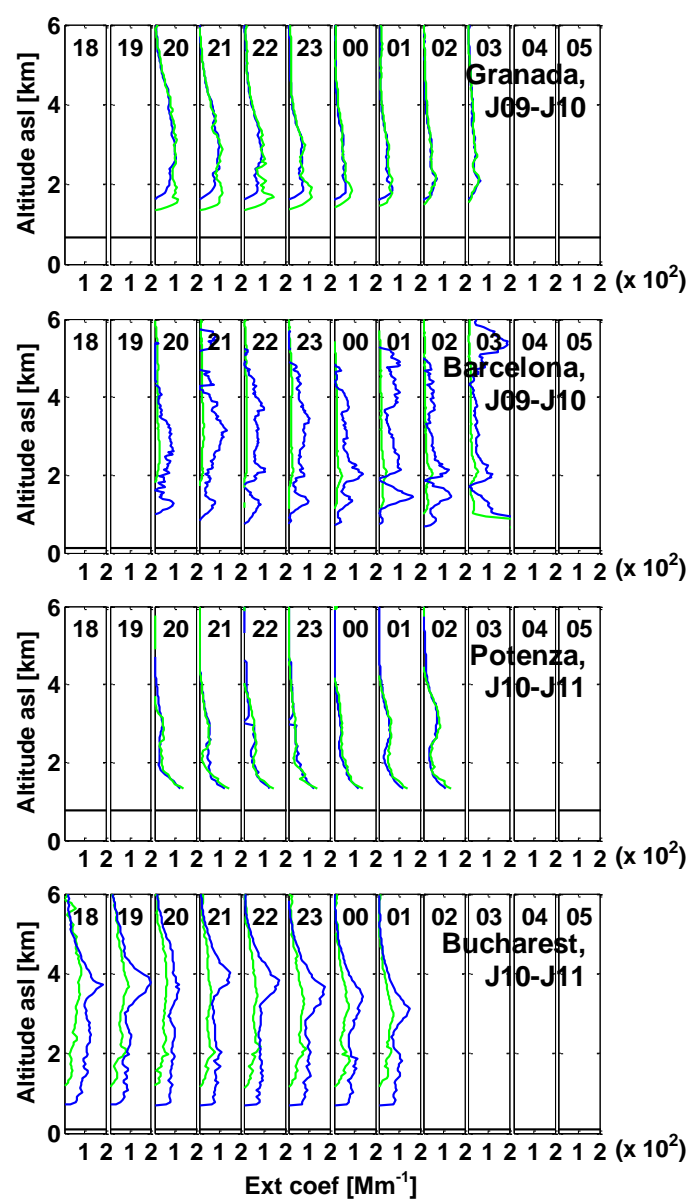

Figure 9. Time series of Raman-inverted extinction coefficient profiles (SCC-2 product) at 355 (blue) and $532 \mathrm{~nm}$ (green). The numbers below the top axis indicate the time in UT. The horizontal black lines represent the station's altitude asl.

tions of the Iberian Peninsula (GR and BA on the night J09$\mathrm{J} 10)$ and at two stations of central and eastern Europe (PO and $\mathrm{BU}$ on the night $\mathrm{J} 10-\mathrm{J} 11$ ). The plots at $\mathrm{PO}$ and $\mathrm{BU}$ are shown $24 \mathrm{~h}$ after the selected night at GR and BA in order to maximize the probability of presence of mineral dust in the profiles (see Fig. 4). As it can be seen in Fig. 9, the temporal continuity of the retrieved profiles reveals the correct functioning of the SCC in nighttime conditions.

All extinction profiles stay generally below $200 \mathrm{Mm}^{-1}$. Low spectral dependency between both profiles at 355 and at $532 \mathrm{~nm}$ is observed at GR above $2 \mathrm{~km}$ and at PO in the whole profile, and indicates the presence of mineral dust at both stations. In BA, the profiles at both wavelengths are quite different and suggest different signal levels: the large oscillations at $355 \mathrm{~nm}$ reflect lower SNR compared to $532 \mathrm{~nm}$. In BU, the extinction coefficient is almost twice as large at $355 \mathrm{~nm}$ than at $532 \mathrm{~nm}$. The large spectral dependency observed on the extinction coefficient in both $\mathrm{BA}$ and $\mathrm{BU}$ is consistent with the high AE found on the AERONET data (1.4-1.7 in
BA and 1-1.2 in BU; Granados-Muñoz et al., 2015). In BU, an aerosol layer is clearly visible up to $2 \mathrm{~km}$ and another one up to $5-6 \mathrm{~km}$, reaching peak values at heights between 3 and $4 \mathrm{~km}$. Those vertical profiles of optical properties are in agreement with the microphysical retrievals presented in Granados-Muñoz et al. (2015) who found a strong contribution of non-spherical coarse particles in the lofted layers on J09 in GR, and a strong contribution of fine particles in the lofted layers on J11 in BU.

\subsubsection{Parameters derived from the SCC-2 products}

The Raman and the multi-wavelength capabilities of the advanced systems allow for the retrieval of derived products such as

- the backscatter-related $\mathrm{AE}$ between the wavelengths $\left(355,532 \mathrm{~nm} ; \mathrm{AE}_{355-532}\right),\left(532,1064 \mathrm{~nm} ; \mathrm{AE}_{532-1064}\right)$ and $\left(355,1064 \mathrm{~nm} ; \mathrm{AE}_{355-1064)}\right.$

- the extinction-related $\mathrm{AE}$ between the wavelengths $(355,532 \mathrm{~nm})$

- the lidar ratios (LR), the extinction-to-backscatter ratio, at $355\left(\mathrm{LR}_{355}\right)$ and at $532 \mathrm{~nm}\left(\mathrm{LR}_{532}\right)$

- the color ratios, the ratio of the backscatter coefficients, between the wavelengths $\left(355,532 \mathrm{~nm} ; \mathrm{CR}_{355-532}\right)$, (532, $1064 \mathrm{~nm} ; \mathrm{CR}_{532-1064)}$ and $(355,1064 \mathrm{~nm}$; CR $355-1064)$.

The color ratios and the backscatter-related $\mathrm{AE}$ have the same physical meaning, thus the color ratios are listed here and presented in Fig. 10 only for completeness and are not discussed in the text. It is worth noting that those four derived products are all intensive aerosol parameters that are extremely valuable for aerosol classification (Müller et al., 2007b; Burton et al., 2012; Groß et al., 2013). Figure 10 shows all nighttime direct and derived SCC- 2 products at the same stations as in Fig. 9 and for a selected time during the night J09-J10 at the Iberian stations and during J10-J11 at the other two stations. The SCC-2 products were not manipulated so that at high altitude, in aerosol-free regions, some products (AE, LR and CR) stop having a physical meaning. By plotting backscatter and extinction coefficients side by side, the overlap effect present in the first hundreds of meters of the extinction coefficient profile (and not on the backscatter coefficient profile) is shown. We recall that for that reason, the first hundreds of meters above the lidar stations of the profiles of the extinction coefficient and the products derived from them are not representative of the aerosol load. In order to have an idea of the origins of the air masses at each site, 4-day back trajectories were calculated at three heights within the observed aerosol layers with the Hybrid Single Particle Lagrangian Integrated Trajectory (HYSPLIT) model (Draxler and Rolph, 2003; Rolph, 2003) provided by 

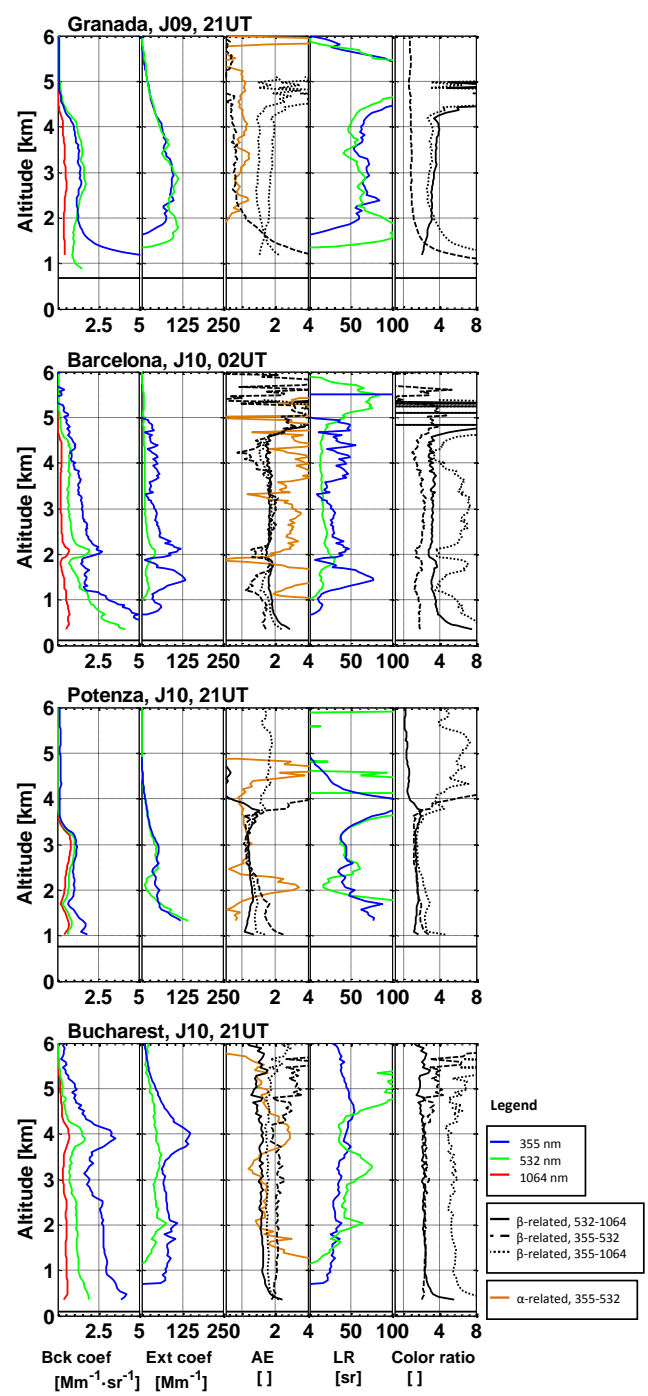

Figure 10. All optical products (SCC-2 direct and derived products) at a selected time. The legend is the same for all the plots and is reported in the bottom right corner. The horizontal black lines represent the station's altitude asl.

the NOAA-ARL (National Oceanic and Atmospheric Administration - Air Resources Laboratory). They are shown in Fig. 11.

The backscatter and extinction coefficients retrieved by the SCC were compared to the manual inversions provided by each group. In GR, one difference appears between the SCC profiles and the manual inversions provided by the Granada group (not shown): the SCC profile of the backscatter coefficient at $1064 \mathrm{~nm}$ is lower (by a roughly constant value of -1.2 to $-1.0 \mathrm{Mm}^{-1} \mathrm{sr}^{-1}$ ) with respect to the manual inversions. This discrepancy is mainly due to different approaches used to calibrate the backscatter coefficient at $1064 \mathrm{~nm}$. The SCC calibration is made following the procedure provided by Mattis at al. (2015) constraining, within the calibration range, the aerosol backscatter coefficient to a fixed climatological value. On the other hand, the calibration of the manually inverted backscatter coefficient at $1064 \mathrm{~nm}$ is made according to Engelmann et al. (2015). In particular, the information available at other wavelengths $(355$, and $532 \mathrm{~nm}$ in this case) is used to constrain the aerosol backscatter reference at $1064 \mathrm{~nm}$. This approach cannot be used by the SCC because, in the current version, it does not implement retrieval procedures combining aerosol products calculated at different wavelengths. In the framework of the ongoing ACTRIS2 project, EARLINET is working to implement such advanced analysis procedures in the SCC and also to set up a multi-wavelength post-retrieval quality check for both manual and SCC inversions. In BA, the agreement between SCC and manual retrievals is good, even though larger variations, probably due to different vertical resolutions, are observed on the manual retrievals. In PO, the agreement between SCC and manual retrievals is very good. Only one significant discrepancy, which might also be due to different vertical resolutions, is observed on the extinction coefficient at $532 \mathrm{~nm}$ in the range $1.7-2.5 \mathrm{~km}$ which is in average around $15 \mathrm{Mm}^{-1}$ for the SCC and $35 \mathrm{Mm}^{-1}$ for the manual inversion. Finally, in BU the agreement between SCC and manual retrievals is very good. No significant differences are observed. It is worth noting that D'Amico et al. (2015b), who performed systematic comparisons between SCC and manual retrievals, show that there is no climatological bias between both retrievals.

As far as the aerosol 4-D characterization is concerned, the analysis of Figs. 10 and 11 gives an insight about the possible aerosol type observed at each site. In GR, two layers are detected: one below $2 \mathrm{~km}$ and another one above up to $4-4.5 \mathrm{~km}$. Above $2 \mathrm{~km}$ the extinction coefficient profiles at 355 and at $532 \mathrm{~nm}$ overlap, which results in an extinctionrelated AE close to 0 . This low value of the extinction-related $\mathrm{AE}$ indicates the presence of large particles such as mineral dust. The back trajectories at 2.5 and $4 \mathrm{~km}$ originate along the coasts of Morocco where dust is detected on the MSG/SEVIRI AOD maps (Fig. 4). The back trajectories arriving in GR at $1500 \mathrm{~m}$ seems to have a north Atlantic origin. Except for a peak at $80 \mathrm{sr}, \mathrm{LR}_{355}$ varies between 55 and 70 sr while $L_{532}$ varies between 45 and 65 sr between 2 and $4 \mathrm{~km}$. The values found for the lidar ratios and the extinctionrelated $\mathrm{AE}$ are in agreement with previous observations of Saharan dust in GR (Guerrero-Rascado et al., 2008, 2009; Córdoba-Jabonero et al., 2011). In BA, several layers are observed up to $\sim 4.5 \mathrm{~km}$. The backscatter-related AE are quite variable from one pair of wavelengths to another, while the extinction-related $\mathrm{AE}$ is often larger than 2 , a value quite larger than the mean summer value of 0.82 given by Sicard et al. (2011). $\mathrm{LR}_{355}$ varies between 30 and 45 sr while $\mathrm{LR}_{532}$ varies in the range $15-30 \mathrm{sr}$. An a posteriori verification on the SCC-1 profiles reveals a small contamination of clouds in the layer centered at $1.5 \mathrm{~km}$. The back trajectories shown in Fig. $11 \mathrm{~b}$ indicate that the air masses arriving in BA at $1.5 \mathrm{~km}$ have a local origin (re-circulation patterns) while those ar- 

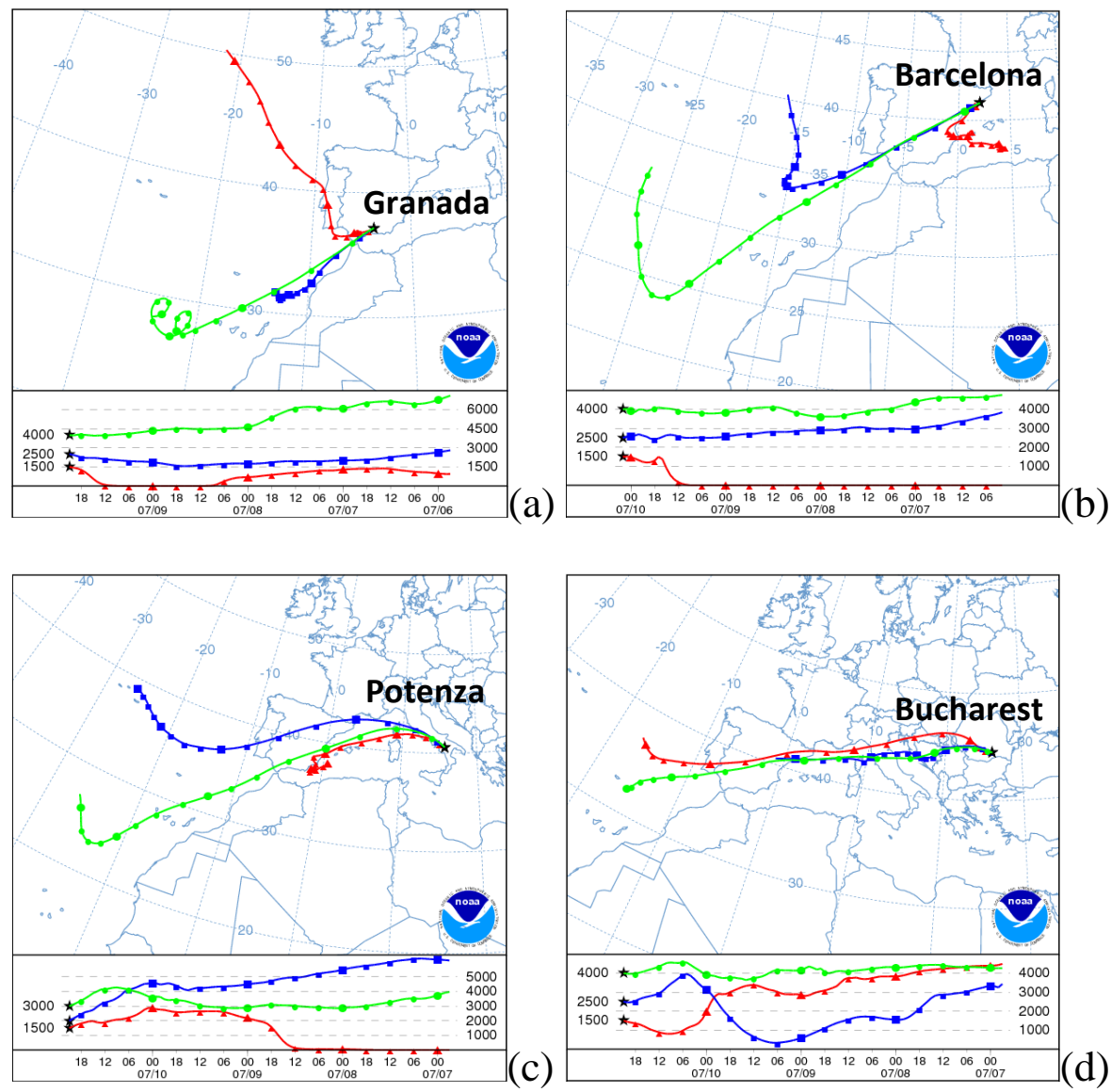

Figure 11. HYSPLIT 4-day back trajectories (a) in Granada on J09 at 21:00 UT, (b) in Barcelona on J10 at 02:00 UT, (c) in Potenza on J10 at 21:00 UT and (d) in Bucharest on J10 at 21:00 UT.

riving at 2.5 and $4 \mathrm{~km}$ have a clear origin over the Atlantic Ocean. In spite of the large variability of the aerosol intensive parameters derived from the SCC-2 products, the results obtained (large extinction-related $\mathrm{AE}$ and low $\mathrm{LR}_{532}$ ) together with the back trajectories indicate that marine aerosols are likely mixed with local polluted particles. From the backscatter coefficient profiles in $\mathrm{PO}$, three aerosol layers stand out: one up to $1.7 \mathrm{~km}$, a second one between 1.7 and $2.5 \mathrm{~km}$ and another one between 2.5 and $3.5 \mathrm{~km}$. One observes that the higher the aerosol layer, the lower the spectral dependency. This behavior is well reproduced on the backscatter-related $\mathrm{AE}$ that decrease with increasing height and that are similar and lower than 1 at almost all heights. In the uppermost layer, $(2.5-3.5 \mathrm{~km})$ all AEs are lesser than 0.5. The lidar ratios in the same interval range are similar and vary between 40 and 55 sr. Those results (low AE; $40<$ LR $<55$ sr) reveal the presence of mineral dust in the aerosol layer between 2.5 and $3.5 \mathrm{~km}$, a conclusion that is confirmed by the back trajectories arriving in $\mathrm{PO}$ at $3 \mathrm{~km}$ (Fig. 11c) which originate along the coasts of Morocco where dust is present (see the MSG/SEVIRI AOD maps in Fig. 4). These results are in agreement with previous studies on Saharan dust obser- vations over PO by Mona et al. (2006, 2014). Over about 6 years of Raman measurements $L_{532}$ for dust (pure and mixed situations) is found to be in the range 40-70 sr and typically increases with decreasing AE (Mona et al., 2014). In $\mathrm{BU}$, two main layers are visible on the backscatter coefficient profiles: one between 1.0 and $2.5 \mathrm{~km}$ and another one centered around $4 \mathrm{~km}$. A clear spectral dependency arises from the optical coefficients resulting in Ångström exponents relatively high. The lidar ratios are slightly different between one layer and the other: $\mathrm{LR}_{355} \sim 30 \mathrm{sr}$ and $\mathrm{LR}_{532} \sim 40 \mathrm{sr}$ in the range interval $2-3 \mathrm{~km}$ while $\mathrm{LR}_{355} \sim 45 \mathrm{sr}$ and $\mathrm{LR}_{532} \sim 38 \mathrm{sr}$ in the layer centered around $4 \mathrm{~km}$. All three back trajectories arriving in BU at 1.5, 2.5 and $4 \mathrm{~km}$ come from the same direction: west-southwest. According to Burton el al. (2012) the combination of $\mathrm{AE}_{532-1064} \sim 1.1$ (which represents a color ratio 532/1064 nm near 2) and $\mathrm{LR}_{532} \sim 40 \mathrm{sr}$ (at 2-3 km) and around $38 \mathrm{sr}$ (in the layer centered around $4 \mathrm{~km}$ ) could indicate urban aerosols and/or smoke at $2-3 \mathrm{~km}$ and fresh smoke in the uppermost layer. MODIS fire maps (Fig. 4) on J09 and J10 indicate the presence of fires in southern France and in the northern Balkan countries. Our results are in agreement with observations of fresh and aged biomass burning 
in BU (Nicolae et al., 2013), in which fresh and aged smoke particles are distinguished by means of their Ångström exponents and the ratio of their lidar ratios $\left(\mathrm{LR}_{532} / \mathrm{LR}_{355}\right)$. Also Granados-Muñoz et al. (2015) found that the aerosol size distribution in BU was dominated by small particles, especially on J11.

\subsection{Example 2: evaluation of dust transport models}

Another outcome of the operationality exercise is the evaluation of aerosol transport model. Since the western and central Mediterranean Basin was hit by an intrusion of Saharan dust, the exercise is an excellent tool for examining the performance of dust transport models. This section aims at illustrating how SCC-2 products, namely the vertical profiles of extinction coefficient, can be used to examine the performance of dust transport models to predict the 4-D evolution of mineral dust during a dust intrusion event. Literature is available on the subject (Gobbi et al., 2013; Mona et al., 2014; Binietoglou et al., 2015, among others), so that, again, the emphasis is put more on the potential of SCC-2 products for the evaluation of aerosol transport models than on the proper evaluation of the selected dust transport models during the exercise.

Two models participated in this evaluation: BSC DREAM8b v2 (Pérez et al., 2006a, b; Basart et al., 2012) and NMMB/BSC-DUST (Nonhydrostatic Multiscale Meteorological Model on the B grid/Barcelona Supercomputing Center - Dust; Janjic et al., 2011; Pérez et al., 2011). Both models are developed and operated at the Barcelona Supercomputing Center (BSC), Spain. Table 4 summarizes the main parameters used in the configuration of the models. More details about their physical parametrizations (source mask and emission and deposition schemes) can be found at http://www.bsc.es/earth-sciences/ mineral-dust-forecast-system. The only operational product from the models that can be compared directly to one of the SCC products is the extinction coefficient at $550 \mathrm{~nm}$. The modeled extinction values at $550 \mathrm{~nm}$ are directly compared with the SCC extinction values at $532 \mathrm{~nm}$ because of the wavelength proximity and the low spectral extinction dependence of mineral dust (see Sect. 4.2). In order to avoid making any hypothesis on the relationship between lidar-derived backscatter and extinction coefficients, only extinction coefficients retrieved from the combination of elastic and Raman signals (nighttime, e-files) are used. The vertical resolution of both dust models is much coarser than the lidar vertical resolution. In order to evaluate the models' capability to reproduce the vertical distribution of the dust extinction coefficient, the original lidar vertical resolution is degraded to the resolution of the modeled profiles. For the horizontal resolution, the lidar data can be considered to be punctual observations, while the models represent uniform pixels of $0.3 / 0.25^{\circ}$ resolution $(\sim 33 / 25 \mathrm{~km})$ for BSC-DREAM8b/NNMB/BSCDUST, respectively. The temporal resolution is also different: while the models provide instantaneous profiles (every $1 \mathrm{~h}$ for BSC-DREAM8b and every $3 \mathrm{~h}$ for NNMB/BSC-DUST), the lidar profiles are averaged over $1 \mathrm{~h}$. Here we have compared each modeled profile at time $t$ with the lidar-derived profile averaged over $t+1 \mathrm{~h}$. Finally, the comparison exercise between modeled and observed profiles of the dust extinction coefficient is performed only in the free troposphere. The lower limit of the comparison range was fixed to $2 \mathrm{~km}$. This choice is related to the fact that both models provide only the dust component of the aerosol content, while the lidars measure the whole aerosol content. Both quantities are usually quite different in the PBL. The upper limit was fixed to $7 \mathrm{~km}$ since no dust was detected higher than $7 \mathrm{~km}$ neither in Granada, nor in Potenza.

The comparison is performed at the two sites where the dust was detected and clearly identified: Granada and Potenza. Model and observation comparisons can be performed for many different quantities and in many different ways (Gobbi et al., 2013; Mona et al., 2014; Binietoglou et al., 2015; Granados-Muñoz et al., 2015, among others). In order to avoid applying additional algorithms on the profiles, we discarded the comparison of structural parameters, like the center of mass or the dust layer thickness (which, in addition, are not SCC products). We focused the comparison on the similarities of consecutive, individual profiles of the dust extinction coefficient. For each pair of individual profiles (model, observation) we calculated the following two statistical indicators: the correlation coefficient, $r$, and the fractional bias, $F_{\mathrm{B}}$. The linear correlation coefficient is a measure of the models' capability to reproduce the shape of the aerosol profile. The fractional bias is a normalized measure of the mean bias and indicates only systematic errors which lead to an under/overestimation of the measured values.

Figure 12 shows the temporal mean profiles of extinction coefficient. A large standard deviation is associated to the observation since the entire event (from beginning to end) was captured at both sites. Below a given height $(4 \mathrm{~km}$ in Granada and $3.2 \mathrm{~km}$ in Potenza) both models underestimate the extinction coefficient. The main reason is without any doubt the presence of non-dust-type particles mixed with the dust detected in the observations but not taken into account in the models. Mona et al. (2014), who found the same conclusion from the comparison of BSC-DREAM8b and Potenza profiles, suggest an additional explanation which is that the model does not consider internal mixing and modification processes. In Granada, BSC-DREAM8b underestimates the extinction coefficient at all heights, while the agreement between NNMB/BSC-DUST and the observation is quantitatively and qualitatively quite good above $4 \mathrm{~km}$. In Potenza, the agreement between BSC-DREAM8b and the observation in the range $4-6 \mathrm{~km}$ is relatively good, while NNMB/BSC-DUST tends to overestimate the dust extinction coefficient above $4 \mathrm{~km}$. Interestingly, the same tendency of NNMB/BSC-DUST was found by Binietoglou et al. (2015) 
Table 4. Main parameters of the dust transport models used in this study.

\begin{tabular}{|c|c|c|}
\hline & BSC-DREAM8b v2 & NMMB/BSC-DUST \\
\hline Meteorological driver & Eta/NCEP & NMMB/NCEP \\
\hline Model domain & \multicolumn{2}{|c|}{ North Africa-Middle East-Europe $\left(25^{\circ} \mathrm{W}-60^{\circ} \mathrm{E}\right.$ and $\left.0-65^{\circ} \mathrm{N}\right)$} \\
\hline Initial and boundary conditions & \multicolumn{2}{|c|}{$\operatorname{NCEP} / \mathrm{FNL}\left(1^{\circ} \times 1^{\circ}\right)$} \\
\hline Boundary condition update & \multicolumn{2}{|r|}{$6 \mathrm{~h}$} \\
\hline Horizontal resolution & $0.3^{\circ} \times 0.3^{\circ}$ & $0.25^{\circ} \times 0.25^{\circ}$ \\
\hline Vertical resolution & 24 Eta-layers & $40 \sigma$-hybrid layers \\
\hline Time resolution & \multirow{2}{*}{$1 \mathrm{~h}$} & $3 \mathrm{~h}$ \\
\hline Transport size bins & & $8(0.1-10 \mu \mathrm{m})$ \\
\hline Radiation interactions & \multirow[t]{2}{*}{ Yes } & No \\
\hline Data assimilation & & No \\
\hline
\end{tabular}

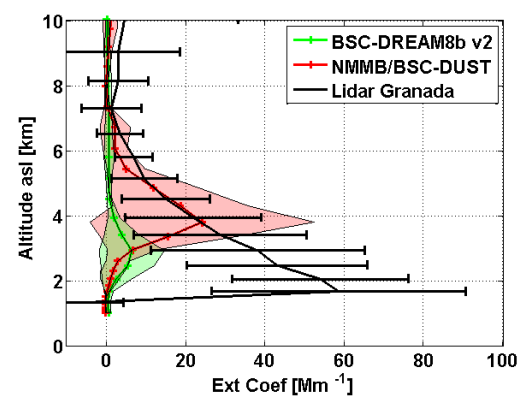

(a)

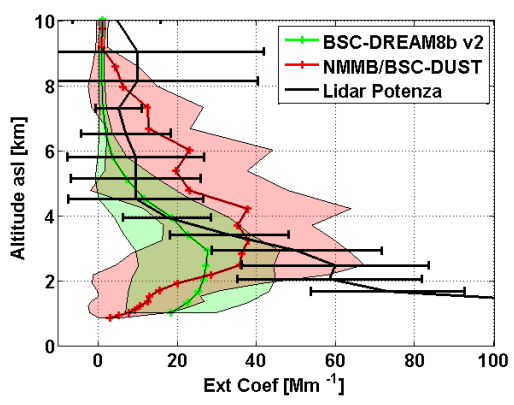

(b)

Figure 12. Mean profiles of the extinction coefficient (a) in Granada and (b) in Potenza. The standard deviation associated to each profile is represented by shaded areas for the models and by horizontal error bars for the lidar measurements.

who found a slight overestimation of NNMB/BSC-DUST above $4.5-5 \mathrm{~km}$ when comparing the model with LIRIC (Lidar-Radiometer Inversion Code) profiles of mass concentration at several sites in Europe.

Figure 13 which shows the correlation coefficient and the fractional bias calculated for each (model, observation) pair offers a finer look at the performance of the model on a case-by-case basis. The combination of both types of plots ( $r$ vs. $F_{\mathrm{B}}$ and $r$ and $F_{\mathrm{B}}$ vs. time) of Fig. 13 allows us to identify at which station and when during the event the models reproduce the observations better. The mean values of $\left(r, F_{\mathrm{B}}\right.$; crosses in Fig. 13a and b) are closer to the ideal pair in Potenza than in Granada for both models. In Potenza, Fig. 13b indicates that BSC-DREAM8b reproduces the shape of the profiles $(r=0.75)$ well and that NNMB/BSC-DUST extinction coefficients are overall on the order of magnitude of that of the observations $\left(F_{\mathrm{B}}=-0.11\right)$. At both stations, the same tendency between both models is observed: BSC-DREAM8b seems to better reproduce the shape of the profiles (higher correlation coefficients), while NNMB/BSC-DUST better reproduces quantitatively the profiles (lower fractional biases). The temporal continuity of SCC-2 products allows us also to follow the models' performances at the model time resolution (Fig. 13c and d). In Granada, relatively high correlation coefficients $(r>0.75$ for BSC-DREAM8b and $0.24<r<0.66$ for NNMB/BSC-
DUST) are observed during the first night of the exercise (J09-J10). From the second night on, $r$ is almost always negative. Except for one outlier, the fractional bias is always negative and lower than -0.58 . Those results indicate that generally, and only for this dust event, both models did not reproduce correctly the chronology of the profiles of the dust extinction coefficient in Granada. In Potenza, the capability of both models to reproduce the shape of the dust layer increases gradually as the event evolves: during the night J11-J12 $r>0.66$ and $r>0.52$ for BSC-DREAM8b and NNMB/BSC-DUST, respectively. Except for two outliers, the fractional bias is always negative. During the night J11-J12 the fractional bias of BSC-DREAM8b reduces significantly: most of the points have a fractional bias between -0.36 and -0.13 . This result, together with the fact that $r>0.66$ during that night, denote the only period during which one of the models (here BSC-DREAM8b) predicts relatively well the profiles of dust extinction coefficient both quantitatively and qualitatively.

In summary, the comparison of dust transport models with SCC-2 products allowed for the evaluation of the capability of the models to predict, correctly or not, the transport of dust during a given dust event. In the present case, both models have generally a hard time in reproducing the event, though better results are observed in the eastern part of the domain and towards the end of the event. The great advantage 

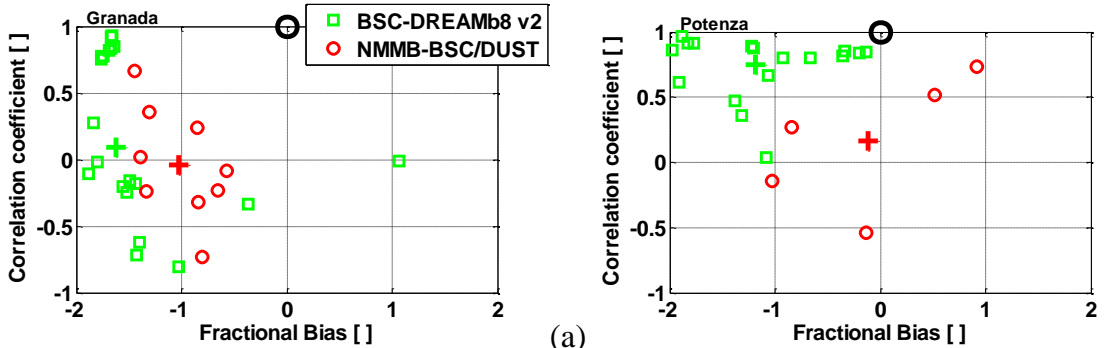

(b)
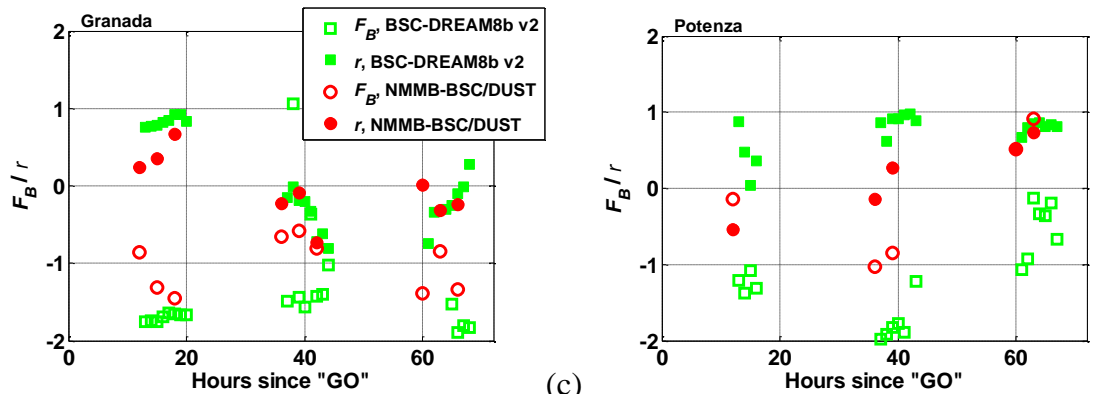

(d)

Figure 13. Correlation coefficient vs. fractional bias (a) in Granada and (b) in Potenza. The crosses indicate the mean values and the black circle indicates the ideal pair $\left(r, F_{\mathrm{B}}\right)=(1,0)$. Correlation coefficient and fractional bias vs. time (c) in Granada and (d) in Potenza.

of this exercise compared to former works that dealt essentially with individual cases is that it may offer the possibility to modelers to improve the performances of their models and consequently to adjust the model schemes for re-analysis.

\subsection{Perspectives offered by the 9-12 July 2012, measurement exercise}

The EARLINET $72 \mathrm{~h}$ measurement exercise performed in July 2012 demonstrates the potential operationality of an aerosol lidar research network formed mostly by advanced lidar systems. SCC-1 and SCC-2 products for this field campaign have been processed and are available to the scientific community on request. More details about the EARLINET data policy can be found in the EARLINET website (http://www.earlinet.org/).

Even if the exercise duration is rather short, it demonstrates that all techniques, infrastructures, and procedures are ready for the operationality of the network. The only limiting factor is the cost of operation. In that line, the automation or semi-automation of many EARLINET advanced lidar systems is ongoing in order to decrease drastically the cost of operation. The data from the EARLINET $72 \mathrm{~h}$ measurement exercise, SCC-1 products in this case, partly or as a whole, are also used by the EARLINET community itself for investigating new retrieval methods (Bravo-Aranda et al., 2014; Banks et al. 2014) and evaluating different PBL schemes in the Weather Research and Forecasting (WRF) model (Banks et al., 2015). The results from the exercise allow us to tackle many fields related to atmospheric aerosols: monitoring of special events (Saharan dust intrusions, spread of volcanic ash plumes, transport of biomass burning or export of contamination), atmospheric modeling (air quality models, dust transport models, numerical dispersion and weather models), climate research (model evaluation at the scale of the event, aerosol transport and tracers, impact on radiation) and calibration/validation activities of spaceborne lidars.

\subsubsection{Monitoring of special events}

The specific observations performed by EARLINET during special events such as Saharan dust outbreaks, volcanic eruptions and biomass burning (see references in the introduction) are not continuous measurements. Even if today those measurements can be processed by the SCC in near-real time fulfilling simultaneously the quality standards of EARLINET (D'Amico et al., 2015a, b), their temporal discontinuity and heterogeneity would make the spatiotemporal monitoring of a special event difficult. By applying the measurement protocol defined in Sect. 2.2, EARLINET is able to perform continuous measurements in order to provide real time SCC-1 products. This capability has a tremendous outcome for what concerns continental scale volcanic eruptions such as the one of the Eyjafjallajökull volcano in 2010 (Ansmann et al., 2010; Groß et al., 2011; Sicard et al., 2012; Pappalardo et al., 2013, among others). Such events, which represent a hazard for a large number of human activities, could be monitored firstly in real time (SCC-1 products) for their spatiotemporal distribution and secondly in near-real time (SCC2 products) for quantifying the aerosol optical properties and concentration. 


\subsubsection{Atmospheric modeling}

In the field of atmospheric modeling real time SCC-1 and near-real-time SCC-2 products are also of great interest, in particular for air quality, dust transport, and numerical dispersion and weather forecasts.

Recent air quality modeling studies have shown that the assimilation of ground-based $\mathrm{PM}_{10}$ measurements by a mesoscale chemical-transport model only constrains the model over a few hours and does not improve the forecast over time scales larger than $24 \mathrm{~h}$ (Tombette et al., 2009). In situ surface measurements also do not provide information on the vertical profiles. Although the persistence of forecast improvement of $\mathrm{PM}_{10}$ is short when ground-based $\mathrm{PM}_{10}$ measurements are assimilated, the assimilation of lidar measurements is expected to lengthen the time scale over which the forecast may be improved, by adding information on the vertical concentration of particles and constraining the transport. Indeed, the EARLINET $72 \mathrm{~h}$ measurement exercise already led to significant results in that field: Wang et al. (2014) assimilated the SCC-1 products in the Eulerian chemistry transport model POLAIR3D (Sartelet et al., 2007) of the air quality platform POLYPHEMUS (Mallet et al., 2007). Their findings indicate that a horizontal correlation length of $100 \mathrm{~km}$, an assimilation altitude range of $1-3.5 \mathrm{~km}$ and an assimilation period length of $12 \mathrm{~h}$ give the best scores for $\mathrm{PM}_{10}$ and $\mathrm{PM}_{2.5}$. Additionally, the authors find that the temporal impact of assimilating lidar signals is longer than $36 \mathrm{~h}$ after the assimilation period. The advantage of using SCC-1 products is that they are generated with a higher success rate than SCC-2 products. For example, in the present exercise, $98 \%$ (against $79 \%$ ) of all submitted files provided SCC-1 (SCC-2) products.

Saharan dust is an important contributor on European air quality levels and consequently has a relevant impact on human health and ecosystems. Even though most of the transport of dust particles occurs in altitude, dust events impact surface $\mathrm{PM}_{10}$ concentrations (Pey et al., 2013), hence the need to model properly their vertical and horizontal transport. Regional dust models need to be evaluated against observations to identify their strengths and weaknesses in reproducing the quantitative and qualitative dust layer properties. The first systematic comparison of modeled dust extinction profiles vs. Raman lidar measurements has been recently published using the BSC-DREAM8b model, one of the most widely used dust regional models in the Mediterranean, and Potenza EARLINET lidar profiles for Saharan dust cases (Mona et al., 2014). More recently GranadosMuñoz et al. (2015) used the EARLINET $72 \mathrm{~h}$ measurement exercise to locally compare in Granada several dust transport models with the observations. At a larger scale, Papayannis et al. (2008) and Binietoglou et al. (2015) reported the comparison of one and four dust transport models, respectively, with EARLINET observations. The evaluation of aerosol models like the SEEVCCC (South East
European Virtual Climate Change Center) DREAM model and the EMEP/MSC-W (EMEP/Meteorological Synthesizing Centre - West) model, with aerosol profiles measured during the whole summer 2012 ACTRIS campaign is currently ongoing (Vukovic et al., 2104; Tsyro et al., 2014). At the regional scale, the EARLINET $72 \mathrm{~h}$ measurement exercise represents a great potential for real-time monitoring, estimation and validation of regional dust models since it provides on a regional scale the structural and optical properties of the dust layers during a continuous period of time. The real-time requirement is an important issue because SCC-2 products are needed for the evaluation of operational dust models. The potential operationality of EARLINET, but not only, is also fundamental for the reliability of mineral dust forecasting and early warning system such as the WMO Sand and Dust Storm Warning Advisory and Assessment System (SDS-WAS) which usually relies on the output of several models (see http://sds-was.aemet.es/).

The use of aerosol data for assimilation in a numerical weather prediction model is very recent: Collins et al. (2001) and Rasch et al. (2001) focused on regional studies while Benedetti et al. (2009) assimilated aerosol data globally. At the global scale, the first attempt was made with aerosol optical depth from satellite sensors. Again, like in air quality modeling, the information on the vertical distribution of the aerosols is not taken into account. As far as we know, aerosol lidar data have never been assimilated in a weather prediction model, the main reason being that the development of aerosol modules for weather prediction model is relatively new. So there is a large community that will be interested, most likely in the near future, in using aerosol lidar data for assimilation in weather prediction models. The EARLINET $72 \mathrm{~h}$ measurement exercise is a great opportunity for weather modelers to investigate the feasibility of lidar data assimilation in weather forecast modeling at the regional scale in a first approach. For the assimilation to be efficient, a lot of research remains to be done in that field, in particular on the coupling of the aerosol module with the meteorology and generally on the aerosol interactions with the atmospheric system as a whole. Related to weather prediction models and special event monitoring, mass densities derived from SCC-2 products during a special event can help to improve the first guess estimates of the aerosol (typically ash, smoke or dust) emissions which are required as input for numerical dispersion models.

\subsubsection{Climate research}

In climate research continuous lidar measurements are of interest for the validation of regional climate modeling at the scale of the event. Once those models have shown their ability to simulate the evolution of aerosols during a given event (e.g., in terms of spatial pattern, daily variability, plume vertical distribution, particle size distribution, etc.), they are usually used to study the impact of dust outbreaks on regional 
climate (Nabat et al., 2015). The EARLINET $72 \mathrm{~h}$ measurement exercise represents an ideal tool for the validation of such models since it provides hourly extinction coefficient profiles (SCC-2 profiles) at several sites around the Mediterranean basin. Real time is not a requirement for such kind of validation.

When radiation flux measurements are not available, SCC2 products can be used to calculate locally the aerosol direct radiative forcing (ADRF) with 1-D radiative transfer models. Continuous measurements offer the possibility to compare on an hourly basis the shortwave and longwave component and quantify the compensation of the shortwave by the longwave, especially during nighttime. In turn, those local estimations of the ADRF can be used to constrain regional climate model.

\subsubsection{Calibration/validation activities of spaceborne lidars}

The validation of ongoing and the preparation of future satellite-based lidars has been and still is a continuous activity of EARLINET that started before the launch in 2006 of the Cloud Aerosol Lidar and Infrared Pathfinder Satellite Observations (CALIPSO) mission. At network level, a measurement plan was developed and optimized. The coordinated efforts permitted to validate at continental scale different CALIPSO products and to foster new improvements in CALIPSO data (e.g. Pappalardo et al., 2010, Wandinger et al., 2011). Collected measurements (The EARLINET publishing group 2000-2010, 2014) were the pillar for investigating the effects of local variability on validation studies (e.g. Mamouri et al., 2009; Mona et al., 2009). Today, EARLINET activities in satellite data validation have increased: investigation of climatological CALIPSO products, and participation in design and optimization of lidar measurements for next-to-come lidar-based satellite missions like ADMAeolus (and EarthCARE (Earth Clouds, Aerosols and Radiation Explorer). Moreover within the Copernicus programme, other sensors will be launched in space for aerosol monitoring at global and continental scale. EARLINET is already committed by the European Space Agency (ESA) for the validation of ADM-Aeolus and Copernicus Sentinel-5 Precursor missions. All those activities will require important efforts for performing, analyzing using measurements for validation studies. The use of the SCC would represent a valuable help for calibration/validation activities of spaceborne lidars by reducing the efforts of data manipulation. In addition, there is an always increasing request for near-real-time validation for which SCC is particularly important as this study demonstrates.

\section{Conclusions}

In the framework of ACTRIS summer 2012 measurement campaign (8 June-17 July 2012), EARLINET organized and performed a controlled exercise of feasibility to demonstrate its potential to perform operational, coordinated measurements. Eleven lidar stations distributed on the northern Mediterranean Basin participated in the exercise which started on 9 July 2012 at 06:00 UT and ended $72 \mathrm{~h}$ later on 12 July at 06:00 UT. This time period was selected in order to track at the regional scale a Saharan dust intrusion forecasted originally to hit first Spain and move eastward during the period of the exercise. The measurement protocol required that the measurements had to be provided at all the wavelengths available at each station and at the system raw temporal and spatial resolutions, without cloud screening and to be sent in real time in a predefined netcdf file format to a centralized server.

For the first time, the single calculus chain developed within EARLINET was used in real time for a multitude of different systems: the pre-processing of the data (ELPP module, SCC-1 products) was performed in real time while the optical processing (ELDA module, SCC-2 products) was performed in near-real time. ELPP was configured in such a way that at the same time that the outputs were stored, an email was automatically sent to the contact point of the originating station. This email gave a real-time feedback from the SCC about the pre-processing status and revealed to be extremely useful for real-time fine tuning the SCC configuration of each individual system and of its associated products. Three parameters of the product configuration revealed themselves as being especially critical for ELDA processing: the detection limit parameter and the maximum allowed statistical errors (below and above $2 \mathrm{~km}$ ). In order to homogenize and guarantee the same order of magnitude of the overall error associated to the final products, independently of the systems, those parameters were set to the same value for all products.

A total of 665 files were sent to the SCC. Out of them the ELPP module pre-processed successfully 650 files (98\%), while the ELDA module processed successfully 527 files (79\%). This percentage is quite large taking into account that no cloud screening was performed on the lidar data. After an a posteriori manual cloud screening this percentage rises to $87 \%$. At the pre-processing level, the raw data quality was not sufficient to pass ELPP quality control tests in two procedures: in applying the gluing algorithm and the dead time correction to photon-counting channels. At the optical processing level, ELDA was unable to finalize the inversion with the required accuracy in two main steps of the processing: in the search of a calibration interval and in the iterative procedure of the method used to invert the backscatter coefficient from elastic signals only. Unsuccessful inversions occurred at $355 \mathrm{~nm}$ in $94 \%$ of the cases (at $1064 \mathrm{~nm}$ in the rest of them). Among the unsuccessful inversions at $355 \mathrm{~nm}, 78 \%$ of them occurred during the elastic inversion 
(daytime) and $22 \%$ during the Raman inversion (nighttime). Low signal-to-noise ratios of the $355 \mathrm{~nm}$ channels, especially during daytime, emerged as a critical issue common to most of the systems involved in the exercise. Some initiatives are already ongoing to tackle some of the problems encountered during the analysis of the $72 \mathrm{~h}$ database: (1) the developers of ELPP are working on the development of a reliable and robust cloud screening (D'Amico et al., 2015a) and (2) in the framework of the ongoing ACTRIS-2 project, EARLINET is working on the setup of a multi-wavelength post-retrieval quality check procedure for both SCC and manual inversions.

The large amount of coordinated observations and their standardized processing yielded an unprecedented data set with many promising perspectives in the field of atmospheric research. The time series of the continuous and homogeneously obtained products of ELDA were used, as an illustration of those perspectives, for the monitoring of a Saharan dust intrusion event and for the evaluation of two dust transport models. Direct and derived SCC-2 products allowed us to identify at which station the dust was present and to follow the temporal evolution of the vertical distribution of its optical properties, while the SCC-2 extinction coefficient profiles allowed us to examine the performances at the event scale of both dust transport models selected for the experiment: BSC DREAM8b and NNMB/BSC-DUST. More generally, the outputs of the exercise are valuable information in fields such as the monitoring of special events, atmospheric modeling, climate research and calibration/validation activities of spaceborne lidars.

The efforts made to define the measurements protocol and to configure properly the SCC makes the operationality exercise repeatable for any of the applications above mentioned. In the meantime, the EARLINET community is working on three aspects that will significantly improve the operationality of the network and the quality of the products delivered in real time by the SCC, at the hardware level, on the capability of daytime Raman measurements and at the software level on cloud screening and on smoothing procedure of daytime data.

Acknowledgements. The financial support for EARLINET in the ACTRIS Research Infrastructure Project by the European Union's Horizon 2020 research and innovation programme under grant agreement no. 654169 and previously under grant agreement no. 262254 in the 7th Framework Programme (FP7/2007-2013) is gratefully acknowledged. Measurements in Barcelona are supported by the Spanish Ministry of Economy and Competitiveness (project TEC2012-34575) and of Science and Innovation project UNPC10-4E and FEDER funds, and by the Department of Economy and Knowledge fo the Catalan autonomous government (grant 2014 SGR 583). Research activities in Granada are supported by the Spanish Ministry of Economy and Competitiveness through the project CGL2013-45410-R and by the Andalusia Regional Government through projects P10-RNM-6299 and P12-RNM-2409. Measurements in Évora were supported by FCT
(Fundação para a Ciência e a Tecnologia) through the project PTDC/GEO-MET/4222/2012 and grants SFRH/BD/47521/2008 and SFRH/BPD/81132/2011. This project has also received funding from the European Union's Seventh Framework Programme for research, technological development and demonstration under grant agreement no. 289923 - ITaRS. The authors gratefully acknowledge the NOAA Air Resources Laboratory (ARL) for the provision of the HYSPLIT transport and dispersion model and READY website (http://www.arl.noaa.gov/ready.html).

Edited by: A. Ansmann

\section{References}

Alados-Arboledas, L., Müller, D., Guerrero-Rascado, J. L., NavasGuzmán, F., Pérez- Ramírez, D., and Olmo, F. J.: Optical and microphysical properties of fresh biomass burning aerosol retrieved by Raman lidar, and star-and sun-photometry, Geophys. Res. Lett., 38, L01807, doi:10.1029/2010GL045999, 2011.

Amiridis, V., Balis, D. S., Giannakaki, E., Stohl, A., Kazadzis, S., Koukouli, M. E., and Zanis, P.: Optical characteristics of biomass burning aerosols over Southeastern Europe determined from UVRaman lidar measurements, Atmos. Chem. Phys., 9, 2431-2440, doi:10.5194/acp-9-2431-2009, 2009.

Amodeo, A., D'Amico, G., Mattis, I., and Freudenthaler, V.: Error calculation for EARLINET products in the context of quality assurance and single calculus chain, Atmos. Meas. Tech. Discuss., in preparation, 2015.

Ansmann, A., Bösenberg, J., Chaikovsky, A., Comerón, A., Eckhardt, S., Eixmann, R., Freudenthaler, V., Ginoux, P., Komguem, P., Linné, H., Ángel López Márquez, M., Matthias, V., Mattis, I., Mitev, V., Müller, D., Music, S., Nickovic, S., Pelon, J., Sauvage, L., Sobolewsky, P., Srivastava, M. K., Stohl, A., Torres, O., Vaughan, G., Wandinger, U., and Wiegner, M.: Long range transport of Saharan dust to northern Europe: the 11-16 October 2001 outbreak with EARLINET, J. Geophys. Res., 108, 4783, doi:10.1029/2003JD003757, 2003.

Ansmann, A., Tesche, M., Groß, S., Freudenthaler, V., Seifert, P., Hiebsch, A., Schmidt, J., Wandinger, U., Mattis, I., Müller, D., and Wiegner, M.: The 16 April 2010 major volcanic ash plume over central Europe: EARLINET lidar and AERONET photometer observations at Leipzig and Munich, Germany, Geophys. Res. Lett., 37, L13810, doi:10.1029/2010GL043809, 2010.

Banks, R. F., Tiana-Alsina, J., Baldasano, J. M., and Rocadenbosch, F.: Retrieval of boundary layer height from lidar using extended Kalman filter approach, classic methods, and backtrajectory cluster analysis, in: Proc. of SPIE Remote Sensing of Clouds and the Atmosphere XIX and Optics in Atmospheric Propagation and Adaptive Systems XVII, edited by: Comerón, A., Kassianov, E. I., Schäfer, K., Picard, R. H., Stein, K., and Gonglewski, J. D., 9242, 92420F, doi:10.1117/12.2072049, 2014.

Banks, R. F., Tiana-Alsina, J., Rocadenbosch, F., and Baldasano, J. M.: Performance evaluation of boundary layer heights from lidar and the Weather Research and Forecasting model at an urban coastal site in the northeast Iberian Peninsula, Bound.-Lay. Meteorol., 15, 1-28, doi:10.1007/s10546-015-0056-2, 2015.

Basart, S., Pérez, C., Nickovic, S., Cuevas, E., Schulz, M., and Baldasano, J. M.: Development and evaluation of BSC- 
DREAM8b dust regional model over Northern Africa, the Mediterranean and the Middle East regions, Tellus B, 64, 18539, doi:10.3402/tellusb.v64i0.18539, 2012.

Belegante, L., Bravo-Aranda, J.A., Freudenthaler, V., Nicolae, D., Talianu, C., Alados-Arboledas, L., Amodeo, A., Pappalardo, G., Engelmann, R., Baars, H., Wandinger, U., Papayannis, A., Kokkalis, P., and Pereira, S. N.: Experimental assessment of the lidar polarizing sensitivity in aerosol typing studies, Atmos. Meas. Tech. Discuss., in preparation, 2015.

Benedetti, A., Morcrette, J.-J., Boucher, O., Dethof, A., Engelen, R. J., Fisher, M., Flentje, H., Huneeus, N., Jones, L., Kaiser, J. W., Kinne, S., Mangold, A., Razinger, M., Simmons, A. J., and Suttie, M.: Aerosol analysis and forecast in the European Centre for Medium-Range Weather Forecasts Integrated Forecast System: 2. Data assimilation, J. Geophys. Res., 114, D13205, doi:10.1029/2008JD011115, 2009.

Binietoglou, I., Basart, S., Alados-Arboledas, L., Amiridis, V., Argyrouli, A., Baars, H., Baldasano, J. M., Balis, D., Belegante, L., Bravo-Aranda, J. A., Burlizzi, P., Carrasco, V., Chaikovsky, A., Comerón, A., D’Amico, G., Filioglou, M., Granados-Muñoz, M. J., Guerrero-Rascado, J. L., Ilic, L., Kokkalis, P., Maurizi, A., Mona, L., Monti, F., Muñoz-Porcar, C., Nicolae, D., Papayannis, A., Pappalardo, G., Pejanovic, G., Pereira, S. N., Perrone, M. R., Pietruczuk, A., Posyniak, M., Rocadenbosch, F., Rodríguez-Gómez, A., Sicard, M., Siomos, N., Szkop, A., Terradellas, E., Tsekeri, A., Vukovic, A., Wandinger, U., and Wagner, J.: A methodology for investigating dust model performance using synergistic EARLINET/AERONET dust concentration retrievals, Atmos. Meas. Tech., 8, 3577-3600, doi:10.5194/amt-83577-2015, 2015.

Böckmann, C., Wandinger, U., Ansmann, A., Bösenberg, J., Amiridis, V., Boselli, A., Delaval, A., De Tomasi, F., Frioud, M., Hågård, A., Horvat, M., Iarlori, M., Komguem, L. Kreipl, S., Larchevêque, G., Matthias, V., Papayannis, A., Pappalardo, G., Rocadembosch, F., Rodriguez, J. A., Schneider, J., Shcherbakov, V., and Wiegner, M.: Aerosol lidar intercomparison in the framework of the EARLINET project. 2. Aerosol backscatter algorithms, Appl. Opt., 43, 977-989, 2004.

Bösenberg, J., Ansmann, A., Baldasano, J. M., Balis, D., Böckmann, C., Calpini, B., Chaikovsky, A., Flamant, P., Hagard, A., Mitev, V., Papayannis, A., Pelon, J., Resendes, D., Schneider, J., Spinelli, N., Trickl, T., Vaughan, G., Visconti, G., and Wiegner, M.: EARLINET: a European Aerosol Research Lidar Network, in: Advances in Laser Remote Sensing, edited by: Dabas, A., Loth, C., and Pelon, J., Ecole polytechnique, Palaiseau Cedex, France, 155-158, 2001.

Böckmann C., U. Wandinger, A. Ansmann, J. Bösenberg, V. Amiridis, A. Boselli, A. Delaval, F. De Tomasi, M. Frioud, A. Hågård, M. Horvat, M. Iarlori, L. Komguem, S. Kreipl, G. Larchevêque, V. Matthias, A. Papayannis, G. Pappalardo, F. Rocadembosch, J.A. Rodriguez, J. Schneider, V. Shcherbakov, M. Wiegner, "Aerosol lidar intercomparison in the framework of the EARLINET project. 2. Aerosol backscatter algorithms", Appl. Opt. 43, 977-989, 2004.

Bravo-Aranda, J. A.: Lidar depolarization technique: Assessment of the hardware polarizing sensitivity and applications, $\mathrm{PhD}$ Thesis, University of Granada, Department of Applied Physics, ISBN: 978-84-9083-080-2, http://0-hera.ugr.es.adrastea.ugr.es/tesisugr/ 23799109.pdf, 2014.
Bravo-Aranda, J. A., Belegante, L., Freudenthaler, V., AladosArboledas, A., Nicolae, D., Amodeo, A., D’Amico, G., Engelmann, R., Kokkalis, P., Papayannis, A., and Wandinger, U.: Assessment of lidar depolarization uncertainties by means of lidar polarizing sensitivity simulator, Atmos. Meas. Tech. Discuss., in preparation, 2015.

Burton, S. P., Ferrare, R. A., Hostetler, C. A., Hair, J. W., Rogers, R. R., Obland, M. D., Butler, C. F., Cook, A. L., Harper, D. B., and Froyd, K. D.: Aerosol classification using airborne High Spectral Resolution Lidar measurements - methodology and examples, Atmos. Meas. Tech., 5, 73-98, doi:10.5194/amt-5-73-2012, 2012.

Carnuth, W., Kempfer, U., and Trickl, T.: Highlights of the Tropospheric Lidar Studies at IFU within the TOR Project, Tellus B, 54, 163-185, 2002.

Chaikovsky, A., Dubovik, O., Goloub, P., Tanré, D., Pappalardo, G., Wandinger, U., Chaikovsky, A., Denisov, D., Grudo, Y., Lopatsin, A., Karol, Y., Lapyonok, T., Amiridis, V., Ansmann, A., Apituley, A., Alados-Arboledas, L., Binietoglou, I., Freudenthaler, V., Kokkalis, P., Granados Muñoz, M. J., Nicolae, D., Papayannis, A., Perrone, M. R., Pietruczuk, A., Pisani, G., Rocadenbosch, F., Sicard, M., Talianu, C., De Tomasi, F., Tsekeri, A., Wagner, J., and Wang, X.: Algorithm and software package for the retrieval of vertical aerosol properties in the atmospheric column using combined lidar/photometer data, Atmos. Meas. Tech. Discuss., in preparation, 2015.

Christensen, J. H.: The Danish Eulerian hemispheric model - A three-dimensional air pollution model used for the Arctic. Atmos. Environ., 31, 4169-4191, 1997.

Collins, W. D., Rasch, P. J., Eaton, B. E., Khattatov, B. V., and Lamarque, J.-F.: Simulating aerosols using a chemical transport model with assimilation of satellite aerosol retrievals: Methodology for INDOEX, J. Geophys. Res., 106, 7313-7336, 2001.

Córdoba-Jabonero, C., Sorribas, M., Guerrero-Rascado, J. L., Adame, J. A., Hernández, Y., Lyamani, H., Cachorro, V., Gil, M., Alados-Arboledas, L., Cuevas, E., and de la Morena, B.: Synergetic monitoring of Saharan dust plumes and potential impact on surface: a case study of dust transport from Canary Islands to Iberian Peninsula, Atmos. Chem. Phys., 11, 3067-3091, doi:10.5194/acp-11-3067-2011, 2011.

D’Amico, G., Binietoglou, I., Amodeo, A., Pappalardo, G., Baars, H., Engelmann, R., Wandinger, U., Mattis, I., Freudenthaler, V., Wiegner, M., Nicolae, D., Chaikovsky, A., Apituley, A., and Adam, M.: EARLINET single calculus chain for automatic lidar data processing: first tests on optical products, in: Reviewed and Revised Papers Presented at the 26th International Laser Radar Conference (ILRC 2012), edited by: Papayannis, A., Balis, D., and Amiridis, V., 331-334, 2012.

D’Amico, G., Amodeo, A., Baars, H., Binietoglou, I., Freudenthaler, V., Mattis, I., Wandinger, U., and Pappalardo, G.: EARLINET Single Calculus Chain - general presentation methodology and strategy, Atmos. Meas. Tech. Discuss., 8, 4973-5023, doi:10.5194/amtd-8-4973-2015, 2015a.

D'Amico, G., Amodeo, A., Mattis, I., Freudenthaler, V., and Pappalardo, G.: EARLINET Single Calculus Chain - technical - Part 1: Pre-processing of raw lidar data, Atmos. Meas. Tech. Discuss., 8, 10387-10428, doi:10.5194/amtd-8-10387-2015, 2015b. 
Di Girolamo, P., Ambrico, P. F., Amodeo, A., Boselli, A., Pappalardo, G., and Spinelli, N.: Aerosol Observations by Lidar in the Nocturnal Boundary Layer, Appl. Opt., 38, 4585-4595, 1999.

Draxler, R. R. and Rolph G. D.: NOAA AirResources Laboratory, Silver Spring, MD, availabla at: http://www.arl.noaa.gov/ready/ hysplit4.html (last access: 2 December 2014), 2003.

Dulac, F., Agacayak, T., Alados Arboledas, L., Alastuey, A., Ameur, Z., Ancellet, G., Assamoi, E.-M., Attié, J.-L., Becagli, S., Beekmann, M., Bergametti, G., Bocquet, M., Bordier, F., Bourrianne, T:, Chazette, P., Chiapello, I., Coddeville, P., Colomb, A., Comerón, A., D’Amico, G., D’Anna, B., Desboeufs, K., Descloitres, J., Diouri, M., Di Biagio, C., Di Sarra, G:, Durand, P., El Amraoui, L., Ellul, R., Fleury, L., Formenti, P., Freney, E., Gerasopoulos, E:, Goloub, P., Guerrero Rascado, J.-L., Guieu, C:, Hadjimitsis, D., Hamonou, E., Hansson, H.C., Iarlori, M., Ioannou, S., Jaumouillé, E., Jeannot, M., Junkermann, W., Keleshis, C., Kleanthous, S., Kokkalis, P., Lambert, D., Laurent, B., Léon, J.-F., Liousse, C., Lopez Bartolome, M., Losno, R., Mallet, M., Mamouri, R.-E., Marchand, N., Menut, L., Mihalopoulos, N., Morales Baquero, R., Nabat, P., Nicolae, D., Nicolas, J., Notton, G., Paoli, C., Papayannis, A., Pappalardo, G:, Pandis, S., Pelon, J., Pey, J., Pont, V., Querol, X., Ravetta, F:, Renard, J.-B., Rizi, V., Roberts, G., Sartelet, K., Savelli, J.-L., Sciare, J., Sellegri, K:, Sferlazzo, D.M., Sicard, M., Smyth, A., Solmon, F., Tanré, D., Tovar Sánchez, A., Verdier, N., Wagner, F:, Wang, Y., Wenger, J., and Yassaa, N.: An update on ChArMEx (the Chemistry-Aerosol Mediterranean Experiment) activities and plans for aerosol studies in the Mediterranean region, in: European Aerosol Conference, Granada, Spain, edited by: Alados Arboledas, L. and Olmo Reyes, F. J., 2-7 September 2012.

Engelmann, R., Guerrero Rascado, J. L., Alados Arboledas, L., Wandinguer, U., Freudenthaler, V., Baars, H., Mattis, I., Groß, S., Pappalardo, G., Amodeo, A., D’Amico, G., Giunta, A., Chaikovsky, A., Osipenko, F., Slesar, A., Nicolae, D., Belegante, L., Serikov, I., Linné, H., Jansen, F., Apituley, A., Wilson, K., Trickl, T., and Rocadenbosch, R.: Calibrated backscatter measurements at $1064 \mathrm{~nm}$ with lidar: Techniques used in EARLINET and ACTRIS, Atmos. Meas. Tech. Discuss., in preparation, 2015.

Espen Yttri, K., Aas, W., Tørseth, K., Kristiansen, N. I., Lund Myhre, C., Tsyro, S., Simpson, D:, Bergström, R., Marečková, K., Wankmüller, R., Klimont, Z., Amman, M., Kouvarakis, G. N., Laj, P., Pappalardo, G., and Prévôt, A.: EMEP Co-operative Programme for Monitoring and Evaluation of the Long-Range Transmission of Air Pollutants in Europe; Transboundary particulate matter in Europe Status report 2012, available at: http://www.actris.net/Portals/ 97/documentation/dissemination/other/emep4-2012.pdf (last access: 9 December 2014), 2012.

Ferrare, R. A., Melfi, S. H., Whiteman, D. N., Evans, K. D., and Leifer, R.: Raman lidar measurements of aerosol extinction and backscattering: 1. Methods and comparisons, J. Geophys. Res., 103, 19663-19672, 1998.

Freudenthaler, V., Gross, S., Engelmann, R., Mattis, I., Wandinger, U., Pappalardo, G., Amodeo, A., Giunta, A., D’Amico, G:, Chaikovsky, A., Osipenko, F., Slesar, A., Nicolae, D., Belegante, L., Talianu, C., Serikov, I., Linne, H., Jansen, F., Wilson, K., de Graaf, M., Apituley, A., Trickl, T., Giehl, H., Adam, M.: EARLI09 - Direct intercomparison of eleven EARLINET li- dar, in Proc. of the 25th International Laser Radar Conference (ILRC), 5-9 July 2010, 891-894, 2010.

Freudenthaler, V., Linne, H., Chaikovski, A., Groß, S., and Rabus, D.: EARLINET lidar quality assurance tools, Atmos. Meas. Tech. Discuss., in preparation, 2015a.

Freudenthaler, V.: Polarization sensitivity of lidar systems and the $90^{\circ}$-calibration, Atmos. Meas. Tech. Discuss., in preparation, $2015 b$.

GAW Report No. 178 "Plan for the implementation of the GAW Aerosol Lidar Observation Network GALION", WMO/TD-No. 1443, 52 pp., 2008.

Gobbi, G. P., Angelini, F., Barnaba, F., Costabile, F., Baldasano, J. M., Basart, S., Sozzi, R., and Bolignano, A.: Changes in particulate matter physical properties during Saharan advections over Rome (Italy): a four-year study, 2001-2004, Atmos. Chem. Phys., 13, 7395-7404, doi:10.5194/acp-13-7395-2013, 2013.

Granados-Muñoz, M. J., Navas-Guzmán, F., Guerrero-Rascado, J. L., Bravo-Aranda, J. A., Binietoglou, I., Pereira, S. N., Baldasano, J.M., Chaikovsky, A., Comerón, A., Belegante, L., D’Amico, G., Muñoz, C., Nicolae, D., Papayannis, A., Pappalardo, G., Rodríguez, A., Schepanski, K., Sicard, M., Wandinger, U., Olmo, F. J., and Alados-Arboledas, L., Profiles of aerosol microphysical properties during ChArMEx 2012 at European sites, Atmos. Chem. Phys. Discuss., in preparation, 2015.

Groß, S., Freudenthaler, V., Wiegner, M., Gasteiger, J., Geiß, A., and Schnell, F.: Dual-wavelength linear depolarization ratio of volcanic aerosols: lidar measurements of the Eyjafjallajökull plume over Maisach, Germany, Atmos. Environ., 48, 85-96, doi:10.1016/j.atmosenv.2011.06.017, 2011.

Guerrero-Rascado, J.-L., Ruiza, B., and Alados-Arboledas, L. Multi-spectral Lidar characterization of the vertical structure of Saharan dust aerosol over southern Spain, Atmos. Environ., 42, 2668-2681, 2008.

Guerrero-Rascado, J. L., Olmo, F. J., Avilés-Rodríguez, I., NavasGuzmán, F., Pérez-Ramírez, D., Lyamani, H., and Alados Arboledas, L.: Extreme Saharan dust event over the southern Iberian Peninsula in september 2007: active and passive remote sensing from surface and satellite, Atmos. Chem. Phys., 9, 84538469, doi:10.5194/acp-9-8453-2009, 2009.

Hoff, R. M., Bösenberg, J., and Pappalardo, G.: The GAW Aerosol Lidar Observation Network (GALION), International Geoscience and Remote Sensing Symposium (IGARSS-08), Boston (USA), 6-11 July, 2008.

Holben, B., Eck, T. F., Slutsker, I., Tanré, D., Buis, J. P., Setzer, A., Vermote, E., Reagan, J. A., Kaufman, Y. J., Nakajima, T., Lavenu, F., Jankowiak, I., and Smirnov, A.: AERONET - A federated instrument network and data archive for aerosol characterization, Remote Sens. Env., 66, 1-16, 1998.

IPCC: Climate Change 2013, The Physical Science Basis, Working Group I Contribution to the Fifth Assessment Report of the Intergovernmental Panel on Climate Change, edited by: Stocker, T. F., Qin, D., Plattner, G.-K., Tignor, M., Allen, S. K., Doschung, J., Nauels, A., Xia, Y., Bex, V., and Midgley, P. M., Chapter 7: Clouds and Aerosols, 571658, doi:10.1017/CBO9781107415324.016, Cambridge University Press, New York, 2014.

Janjic, Z., Janjic, T., and Vasic, R.: A class of conservative fourthorder advection schemes and impact of enhanced formal ac- 
curacy on extended-range forecasts, Mon. Weather Rev., 139, 1556-1568, doi:10.1175/2010MWR3448.1, 2011.

Landulfo, E., Papayannis, A., Artaxo, P., Castanho, A. D. A., de Freitas, A. Z., Souza, R. F., Vieira Junior, N. D., Jorge, M. P. M. P., Sánchez-Ccoyllo, O. R., and Moreira, D. S.: Synergetic measurements of aerosols over São Paulo, Brazil using LIDAR, sunphotometer and satellite data during the dry season, Atmos. Chem. Phys., 3, 1523-1539, doi:10.5194/acp-3-1523-2003, 2003.

Mamouri, R. E., Amiridis, V., Papayannis, A., Giannakaki, E., Tsaknakis, G., and Balis, D. S.: Validation of CALIPSO spaceborne-derived attenuated backscatter coefficient profiles using a ground-based lidar in Athens, Greece, Atmos. Meas. Tech., 2, 513-522, doi:10.5194/amt-2-513-2009, 2009.

Mamouri, R. E., Ansmann, A., Nisantzi, A., Kokkalis, P., Schwarz, A., and Hadjimitsis, D.: Low Arabian dust extinctionto-backscatter ratio, Geophys. Res. Lett., 40, 4762-4766, doi:10.1002/grl.50898, 2013.

Mallet, V., Quélo, D., Sportisse, B., Ahmed de Biasi, M., Debry, É., Korsakissok, I., Wu, L., Roustan, Y., Sartelet, K., Tombette, M., and Foudhil, H.: Technical Note: The air quality modeling system Polyphemus, Atmos. Chem. Phys., 7, 5479-5487, doi:10.5194/acp-7-5479-2007, 2007.

Masci, F.: Algorithms for the inversion of lidar signals: RayleighMie measurements in the stratosphere, Annali di Geofisica, 42, 71-83, 1999.

Matthias, V., Bösenberg, J., Freudenthaler, V., Amodeo, A., Balis, D., Chaikovsky, A., Chourdakis, G., Comeron, A., Delaval, A., de Tomasi, F., Eixmann, R., Hågård, A., Komguem, L., Kreipl, S., Matthey, R., Mattis, I., Rizi, V., Rodriguez, J. A., Simeonov, V., and Wang, X.: Aerosol lidar intercomparison in the framework of the EARLINET project. 1. Instruments, Appl. Optics, 43, 961-976, 2004.

Mattis, I., Siefert, P., Müller, D., Tesche, M., Hiebsch, A., Kanitz, T., Schmidt, J., Finger, F., Wandinger, U., and Ansmann, A.: Volcanic aerosol layers observed with multiwavelength Raman lidar over central Europe in 2008-2009, J. Geophys. Res., 115, D00L04, doi:10.1029/2009JD013472, 2010.

Mattis, I., Madonna, F., D'Amico, G., Amodeo, A., and Baars, H.: EARLINET-ASOS Single Calculus Chain - technical - Part 2: Calculation of optical products, Atmos. Meas. Tech. Discuss., in preparation, 2015.

Molero, F., Sicard, M., Navas-Guzmán, F., Preißler, J., Amodeo, A., Freudenthaler, V., Fernandez, A. J., Tomas, S., Granados, M. J. Wagner, F., Giunta, A., Mattis, I., Pujadas, M., Comeron, A., Alados-Arboledas, L., Guerrero-Rascado, J. L., D’Amico, G., Lange, D., Bravo, J. A., Kumar, D., Pappalardo, G., Giner, J., Muñoz, C., and Rocadenbosch, F.: Study on aerosol properties over Madrid (Spain) by multiple instrumentation during SPALI10 lidar campaign, Óptica Pura y Aplicada, 45, 405-413, 2012.

Mona, L., Amodeo, A., Pandolfi, M., and Pappalardo, G.: Saharan dust intrusions in the Mediterranean area: three years of Raman lidar measurements, J. Geophys. Res., 111, D16203, doi:10.1029/2005JD006569, 2006.

Mona, L., Pappalardo, G., Amodeo, A., D’Amico, G., Madonna, F., Boselli, A., Giunta, A., Russo, F., and Cuomo, V.: One year of CNR-IMAA multi-wavelength Raman lidar measurements in coincidence with CALIPSO overpasses: Level 1 products com- parison, Atmos. Chem. Phys., 9, 7213-7228, doi:10.5194/acp-97213-2009, 2009.

Mona, L., Papagiannopoulos, N., Basart, S., Baldasano, J., Binietoglou, I., Cornacchia, C., and Pappalardo, G.: EARLINET dust observations vs. BSC-DREAM8b modeled profiles: 12year-long systematic comparison at Potenza, Italy, Atmos. Chem. Phys., 14, 8781-8793, doi:10.5194/acp-14-8781-2014, 2014.

Müller, D., Mattis, I., Ansmann, A., Wandinger, U., Ritter, C., and Kaiser, D.: Multiwavelength Raman lidar observations of particle growth during long-range transport of forest-fire smoke in the free trosposphere, Geophys. Res. Lett., 34, L05803, doi:10.1029/2006GL027936, 2007a.

Müller, D., Ansmann, A., Mattis, I., Tesche, M., Wandinger, U., Althausen, D., and Pisani, G.: Aerosol-type-dependent lidar ratios observed with Raman lidar, J. Geophys. Res., 112, D16202, doi:10.1029/2006JD008292, 2007b.

Nabat, P., Somot, S., Mallet, M., Michou, M., Sevault, F., Driouech, F., Meloni, D., di Sarra, A., Di Biagio, C., Formenti, P., Sicard, M., Léon, J.-F., and Bouin, M.-N.: Dust aerosol radiative effects during summer 2012 simulated with a coupled regional aerosolatmosphere-ocean model over the Mediterranean, Atmos. Chem. Phys., 15, 3303-3326, doi:10.5194/acp-15-3303-2015, 2015.

Navas-Guzmán, F., Müller, D., Bravo-Aranda, J. A., Guerrero- Rascado, J. L., Granados-Muñoz, M. J., Pérez-Ramírez, D., Olmo, F. J., and Alados-Arboledas, L.: Eruption of the Eyjafjallajökull Volcano in spring 2010: Multiwavelength Raman Lidar Measurements of Sulfate Particles in the Lower Troposphere, J. Geophys. Res., 118, 1804-1813, doi:10.1002/jgrd.50116, 2013.

Nickovic S., Papadopoulos A., Kakaliagou O., Kallos G.: A model for prediction of desert dust cycle in the atmosphere, J. Geophys. Res., 106, 18113-18129, 2001.

Nicolae, D., Nemuc, A., Müller, D., Talianu, C., Vasilescu, J., Belegante, L., and Kolgotin, A.: Characterization of fresh and aged biomass burning events using multi-wavelength Raman lidar and mass spectrometry, J. Geophys. Res. Atmos., 118, 2956-2965, doi:10.1002/jgrd.50324, 2013.

Nisantzi, A., Mamouri, R. E., Ansmann, A., and Hadjimitsis, D.: Injection of mineral dust into the free troposphere during fire events observed with polarization lidar at Limassol, Cyprus, Atmos. Chem. Phys., 14, 12155-12165, doi:10.5194/acp-1412155-2014, 2014.

Nisantzi, A., Mamouri, R. E., Ansmann, A., Schuster, G. L., and Hadjimitsis, D. G.: Middle East versus Saharan dust extinctionto-backscatter ratios, Atmos. Chem. Phys., 15, 7071-7084 doi:10.5194/acp-15-7071-2015, 2015.

Papayannis, A., Amiridis, V., Mona, L., Tsaknakis, G., Balis, D., Bösenberg, J., Chaikovski, A., De Tomasi, F., Grigorov, I., Mattis, I., Mitev, V., Müller, D., Nickovic, S., Pérez, C., Pietruczuk, A., Pisani, G., Ravetta, F., Rizi, V., Sicard, M., Trickl, T., Wiegner, M., Gerding, M., Mamouri, R. E., D’Amico, G., and Pappalardo, G.: Systematic lidar observations of Saharan dust over Europe in the frame of EARLINET (2000-2002), J. Geophys. Res., 113, D10204, doi:10.1029/2007JD009028, 2008.

Papayannis, A., Mamouri, R. E., Amiridis, V., Giannakaki, E., Veselovskii, I., Kokkalis, P., Tsaknakis, G., Balis, D., Kristiansen, N. I., Stohl, A., Korenskiy, M., Allakhverdiev, K., Huseyinoglu, M. F., and Baykara, T.: Optical properties and vertical extension of aged ash layers over the Eastern Mediterranean as observed by Raman lidars during the Eyjafjalla- 
jökull eruption in May 2010, Atmos. Environ., 48, 56-65, doi:10.1016/j.atmosenv.2011.08.037, 2012.

Pappalardo G., Amodeo, A., Mona, L., Pandolfi, M., Pergola, N., and Cuomo, V.: Raman lidar observations of aerosol emitted during the 2002 Etna eruption, Geophys. Res. Lett., 31, L05120, doi:10.1029/2003GL019073, 2004a.

Pappalardo, G., Amodeo, A., Pandolfi, M., Wandinger, U., Ansmann, A., Bosenberg, J., Matthias, V., Amiridis, V., De Tomasi, F., Frioud, M., Iarlori, M., Komguem, L., Papayannis, A., Rocadenbosch, F., andWang, X.: Aerosol lidar intercomparison in the framework of the EARLINET project. 3. Raman lidar algorithm for aerosol extinction, backscatter and lidar ratio, Appl. Opt., 43, 5370-5385, 2004b.

Pappalardo, G., Papayannis, A., Bösenberg, J., Ansmann, A., Apituley, A., Alados Arboledas, L., Balis, D., Böckmann, C., Chaikovsky, A., Comeron, A., Gustafsson, O., Hansen, G., Mitev, V., Mona, L., Nicolae, D., Perrone, M. R., Pietruczuk, A., Pujadas, M., Putaud, J.-P., Ravetta, F., Rizi, F., Simeonov, V., Spinelli, N., Stoyanov, D., Trickl, T., Wiegner, M.: EARLINET coordinated lidar observations of Saharan dust events on continental scale. IOP Conf. Ser.: Earth Environ. Sci, 7, 012002, doi:10.1088/1755-1307/7/1/012002, 2009.

Pappalardo, G., Wandinger, U., Mona, L., Hiebsch, A., Mattis, I., Amodeo, A., Ansmann, A., Seifert, P., Linne, H., Apituley, A., Alados Arboledas, L., Balis, D., Chaikovsky, A., D’Amico, G., De Tomasi, F., Freudenthaler, V., Giannakaki, E., Giunta, A., Grigorov, I., Iarlori, M., Madonna, F., Mamouri, R.-E., Nasti, L., Papayannis, A., Pietruczuk, A., Pujadas, M., Rizi, V., Rocadenbosch, F., Russo, F., Schnell, F., Spinelli, N., Wang, X., and Wiegner, M.: EARLINET correlative measurements for CALIPSO: First intercomparison results, J. Geophys. Res., 115, D00H19, doi:10.1029/2009JD012147, 2010.

Pappalardo, G., Mona, L., D’Amico, G., Wandinger, U., Adam, M., Amodeo, A., Ansmann, A., Apituley, A., Alados Arboledas, L., Balis, D., Boselli, A., Bravo-Aranda, J. A., Chaikovsky, A., Comeron, A., Cuesta, J., De Tomasi, F., Freudenthaler, V., Gausa, M., Giannakaki, E., Giehl, H., Giunta, A., Grigorov, I., Groß, S., Haeffelin, M., Hiebsch, A., Iarlori, M., Lange, D., Linné, H., Madonna, F., Mattis, I., Mamouri, R.-E., McAuliffe, M. A. P., Mitev, V., Molero, F., Navas-Guzman, F., Nicolae, D., Papayannis, A., Perrone, M. R., Pietras, C., Pietruczuk, A., Pisani, G., Preißler, J., Pujadas, M., Rizi, V., Ruth, A. A., Schmidt, J., Schnell, F., Seifert, P., Serikov, I., Sicard, M., Simeonov, V., Spinelli, N., Stebel, K., Tesche, M., Trickl, T., Wang, X., Wagner, F., Wiegner, M., and Wilson, K. M.: Four-dimensional distribution of the 2010 Eyjafjallajökull volcanic cloud over Europe observed by EARLINET, Atmos. Chem. Phys., 13, 4429-4450, doi:10.5194/acp-13-4429-2013, 2013.

Pappalardo, G., Amodeo, A., Apituley, A., Comeron, A., Freudenthaler, V., Linné, H., Ansmann, A., Bösenberg, J., D’Amico, G., Mattis, I., Mona, L., Wandinger, U., Amiridis, V., AladosArboledas, L., Nicolae, D., and Wiegner, M.: EARLINET: towards an advanced sustainable European aerosol lidar network, Atmos. Meas. Tech., 7, 2389-2409, doi:10.5194/amt-7-23892014, 2014.

Pérez, C., Nickovic, S., Baldasano, J.M., Sicard, M., Rocadenbosch, F., Cachorro, V.E.: A long Saharan dust event over the western Mediterranean: Lidar, sun photometer observations, and regional dust modeling, J. Geophys. Res., 111, D15214, doi:10.1029/2005JD006579, 2006a.

Pérez, C., Nickovic, S., Pejanovic, G., Baldasano, J.M., Ozsoy, E.: Interactive dust-radiation modeling: A step to improve weather forecasts, J. Geophys. Res., 111, D16206, doi:10.1029/2005JD006717, 1-17, 2006b.

Pérez, C., Haustein, K., Janjic, Z., Jorba, O., Huneeus, N., Baldasano, J. M., Black, T., Basart, S., Nickovic, S., Miller, R. L., Perlwitz, J. P., Schulz, M., and Thomson, M.: Atmospheric dust modeling from meso to global scales with the online NMMB/BSC-Dust model - Part 1: Model description, annual simulations and evaluation, Atmos. Chem. Phys., 11, 1300113027, doi:10.5194/acp-11-13001-2011, 2011.

Pey, J., Querol, X., Alastuey, A., Forastiere, F., and Stafoggia, M.: African dust outbreaks over the Mediterranean Basin during 2001-2011: $\mathrm{PM}_{1} 0$ concentrations, phenomenology and trends, and its relation with synoptic and mesoscale meteorology, Atmos. Chem. Phys., 13, 1395-1410, doi:10.5194/acp-13-13952013, 2013.

Rasch, P. J., Collins, W. D., and Eaton, B. E.: Understanding the Indian Ocean Experiment (INDOEX) aerosol distributions with an aerosol assimilation, J. Geophys. Res., 106, 7337-7355, 2001.

Reba, M. N. M., Rocadenbosch, F., Sicard, M., Kumar, D., and Tomás, S.: On the lidar ratio estimation from the synergy between AERONET sun-photometer data and elastic lidar inversion, Proc. of the 25th International Laser Radar Conference, vol. 2, ISBN 978-5-94458-109-9, Saint-Petersburg (Rusia), 5-9 July 2010, 1102-1105, 2010.

Rolph, G. D.: NOAA Air Resources Laboratory, Silver Spring, MD, http://www.arl.noaa.gov/ready/hysplit4.html (last access: 2 December 2014), 2003.

Roustan, Y., Sartelet, K. N., Tombette, M., Debry, E., and Sportisse, B.: Simulation of aerosols and gas-phase species over Europe with the POLYPHEMUS system, Part II: Model sensitivity analysis for 2001, Atmos. Environ., 44, 4219-4229, 2010.

Sartelet, K. N., Debry, E., Fahey, K. M., Roustan, Y., Tombette, M., and Sportisse, B. : Simulation of aerosols and gas-phase species over Europe with the Polyphemus system. Part I: model-to-data comparison for 2001, Atmos. Env., 29, 6116-6131, 2007.

Sicard, M., Molero, F., Guerrero-Rascado, J. L., Pedrós, R., Expósito, F. J., Córdoba-Jabonero, C., Bolarín, J. M., Comerón, A., Rocadenbosch, F., Pujadas, M., Alados-Arboledas, L., MartinezLozano, J. A., Díaz, J. P., Gil, M., Requena, A., NavasGuzmán, F., and Moreno, J. M.: Aerosol lidar intercomparison in the framework of SPALINET - the SPAnish LIdar NETwork: methodology and results, IEEE Trans. Geosci. Remote Sens., 47, 3547-3559, 2009.

Sicard, M., Rocadenbosch, F., Reba, M. N. M., Comerón, A., Tomás, S., García-Vízcaino, D., Batet, O., Barrios, R., Kumar, D., and Baldasano, J. M.: Seasonal variability of aerosol optical properties observed by means of a Raman lidar at an EARLINET site over Northeastern Spain, Atmos. Chem. Phys., 11, 175-190, doi:10.5194/acp-11-175-2011, 2011.

Sicard, M., Guerrero-Rascado, J. L., Navas-Guzmán, F., Preißler, J., Molero, F., Tomás, S., Bravo-Aranda, J. A., Comerón, A., Rocadenbosch, F., Wagner, F., Pujadas, M., and Alados-Arboledas, L.: Monitoring of the Eyjafjallajökull volcanic aerosol plume over the Iberian Peninsula by means of four EARLINET lidar stations, 
Atmos. Chem. Phys., 12, 3115-3130, doi:10.5194/acp-12-31152012, 2012.

The EARLINET publishing group 2000-2010: Adam, M., AladosArboledas, L., Althausen, D., Amiridis, V., Amodeo, A., Ansmann, A., Apituley, A., Arshinov, Y., Balis, D., Belegante, L., Bobrovnikov, S., Boselli, A., Bravo-Aranda, J. A., Bösenberg, J., Carstea, E., Chaikovsky, A., Comerón, A., D’Amico, G., Daou, D., Dreischuh, T., Engelmann, R., Finger, F., Freudenthaler, V., Garcia-Vizcaino, D., García, A. J. F., Geiß, A., Giannakaki, E., Giehl, H., Giunta, A., de Graaf, M., GranadosMuñoz, M. J., Grein, M., Grigorov, I., Groß, S., Gruening, C., Guerrero-Rascado, J. L., Haeffelin, M., Hayek, T., Iarlori, M., Kanitz, T., Kokkalis, P., Linné, H., Madonna, F., Mamouriat, R.-E., Matthias, V., Mattis, I., Menéndez, F. M., Mitev, V., Mona, L., Morille, Y., Muñoz, C., Müller, A., Müller, D., NavasGuzmán, F., Nemuc, A., Nicolae, D., Pandolfi, M., Papayannis, A., Pappalardo, G., Pelon, J., Perrone, M. R., Pietruczuk, A., Pisani, G., Potma, C., Preißler, J., Pujadas, M., Putaud, J., Radu, C., Ravetta, F., Reigert, A., Rizi, V., Rocadenbosch, F., Rodríguez, A., Sauvage, L., Schmidt, J., Schnell, F., Schwarz, A., Seifert, P., Serikov, I., Sicard, M., Silva, A. M., Simeonov, V., Siomos, N., Sirch, T., Spinelli, N., Stoyanov, D., Talianu, C., Tesche, M., De Tomasi, F., Trickl, T., Vaughan, G., Volten, H., Wagner, F., Wandinger, U., Wang, X., Wiegner, M., and Wilson, K. M.: EARLINET correlative observations for CALIPSO (2006-2010), World Data Center for Climate (WDCC), doi:10.1594/WDCC/EN_Calipso_2006-2010, 2014.

Tombette, M., Mallet, V., and Sportisse, B.: $\mathrm{PM}_{1} 0$ data assimilation over Europe with the optimal interpolation method, Atmos. Chem. Phys., 9, 57-70, doi:10.5194/acp-9-57-2009, 2009.

Tsyro, S., Schulz, M., Mona, L., and Aas, W.: Regional and global calculations of mineral dust with the EMEP model, International Conference on Atmospheric Dust - DUST 2014, 425 pp., Castellaneta Marina (TA), Italy, 1-6 June 2014.

Vukovic, A., Mona, L., Vujadinovic, M., Nickovic, S., Pejanovic, G., Cvetkovic, B., Djordjevic, M., D’amico, G., Papagiannopoulos, N., and Pappalardo, G.: Application of lidar observations in atmospheric dust transport forecast, International Conference on Atmospheric Dust - DUST 2014, Castellaneta Marina (TA), Italy, 1-6 June 2014.

Wagner, J., Ansmann, A., Wandinger, U., Seifert, P., Schwarz, A., Tesche, M., Chaikovsky, A., and Dubovik, O.: Evaluation of the Lidar/Radiometer Inversion Code (LIRIC) to determine microphysical properties of volcanic and desert dust, Atmos. Meas. Tech., 6, 1707-1724, doi:10.5194/amt-6-1707-2013, 2013.
Wandinger, U., Hiebsch, A., Mattis, I., Pappalardo, G., Mona, L., and Madonna, F.: Aerosols and clouds: long-term database from spaceborne lidar measurements, ESTEC Contract 21487/08/NL/HE, Final Report, 235 pp., Leizig, Germany, 2011.

Wandinger, U., Freudenthaler, V., Baars, H., Amodeo, A., Engelmann, R., Mattis, I., Groß, S., Pappalardo, G., Giunta, A., D’Amico, G., Chaikovsky, A., Osipenko, F., Slesar, A., Nicolae, D., Belegante, L., Talianu, C., Serikov, I., Linné, H., Jansen, F., Apituley, A., Wilson, K. M., de Graaf, M., Trickl, T., Giehl, H., Adam, M., Comerón, A., Muñoz, C., Rocadenbosch, F., Sicard, M., Tomás, S., Lange, D., Kumar, D., Pujadas, M., Molero, F., Fernández, A. J., Alados-Arboledas, L., Bravo-Aranda, J. A., Navas-Guzmán, F., Guerrero-Rascado, J. L., Granados-Muñoz, M. J., Preißler, J., Wagner, F., Gausa, M., Grigorov, I., Stoyanov, D., Iarlori, M., Rizi, V., Spinelli, N., Boselli, A., Wang, X., Lo Feudo, T., Perrone, M. R., De Tomasi, F., and Burlizzi, P.: EARLINET instrument intercomparison campaigns: overview on strategy and results, Atmos. Meas. Tech. Discuss., 8, 10473 10522, doi:10.5194/amtd-8-10473-2015, 2015.

Wang, X., Boselli, A., D’Avino, L., Pisani, G., Spinelli, N., Amodeo, A., Chaikovsky, A., Wiegner, M., Nickovic, S., Papayannis, A., Perrone, M. R., Rizi, V., Sauvage, L., and Stohl, A.: Volcanic dust characterization by EARLINET during Etna's eruptions in 2001-2002, Atmos. Environ., 42, 893-905, 2008.

Wang, Y., Sartelet, K. N., Bocquet, M., Chazette, P., Sicard, M., D’Amico, G., Léon, J. F., Alados-Arboledas, L., Amodeo, A., Augustin, P., Bach, J., Belegante, L., Binietoglou, I., Bush, X., Comerón, A., Delbarre, H., García-Vízcaino, D., GuerreroRascado, J. L., Hervo, M., Iarlori, M., Kokkalis, P., Lange, D., Molero, F., Montoux, N., Muñoz, A., Muñoz, C., Nicolae, D., Papayannis, A., Pappalardo, G., Preissler, J., Rizi, V., Rocadenbosch, F., Sellegri, K., Wagner, F., and Dulac, F.: Assimilation of lidar signals: application to aerosol forecasting in the western Mediterranean basin, Atmos. Chem. Phys., 14, 12031-12053, doi:10.5194/acp-14-12031-2014, 2014.

Wiegner, M., Gasteiger, J., Groß, S., Schnell, F., Freudenthaler, V., and Forkel, R.: Characterization of the Eyjafjallajökull ashplume: Potential of lidar remote sensing, Physics and Chemistry of the Earth, 45-46, 79-86, doi:10.1016/j.pce.2011.01.006, 2012. 